\title{
A Blended Empirical Shot Stream Velocity Model for Improvement of Shot Peening Production
}

\section{VAN BO NGUYEN ( $\square$ nguyenvb@ihpc.a-star.edu.sg )}

Institute of High Performance Computing

\section{Augustine Teo}

Data-Driven Surface Enhancement Group, Advanced Remanufacturing and Technology Center, A*STAR, Singapore 637143

\section{$\mathrm{Te} \mathrm{Ba}$}

Fluid dynamics department, Institute of High Performance Computing, A*STAR, Singapore 138632

\section{Ampara Aramcharoen}

Data-Driven Surface Enhancement Group, Advanced Remanufacturing and Technology Center, A*STAR, Singapore 637143

\section{Kunal Ahluwalia}

Data-Driven Surface Enhancement Group, Advanced Remanufacturing and Technology Center, A*STAR, Singapore 637143

\section{Chang Wei Kang}

Fluid dynamics department, Institute of High Performance Computing, A*STAR, Singapore 138632

\section{Research Article}

Keywords: Shot peening, Regression method, Shot stream velocity, Peening intensity, Model predictive control

Posted Date: April 19th, 2021

DOI: https://doi.org/10.21203/rs.3.rs-416780/v1

License: (c) (1) This work is licensed under a Creative Commons Attribution 4.0 International License. Read Full License

Version of Record: A version of this preprint was published at The International Journal of Advanced Manufacturing Technology on September 8th, 2021. See the published version at https://doi.org/10.1007/s00170-021-07972-w. 


\title{
A blended empirical shot stream velocity model for improvement of shot peening production
}

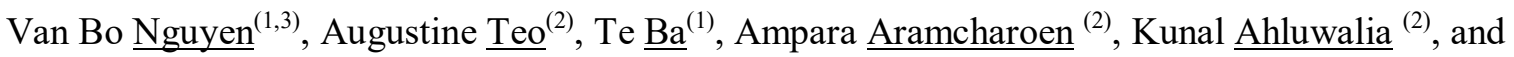 \\ Chang Wei Kang ${ }^{(1)}$ \\ (1) Fluid dynamics department, Institute of High Performance Computing, A*STAR, Singapore 138632 \\ ${ }^{(2)}$ Data-Driven Surface Enhancement Group, Advanced Remanufacturing and Technology Center, \\ A*STAR, Singapore 637143 \\ (3) Temasek Laboratories, National University of Singapore, Singapore 117411
}

Corresponding author: Van Bo Nguyen, Email: nguyenvb@ihpc.a-star.edu.sg, Tel: +65 64191122

\begin{abstract}
Peening intensity and coverage are vital measurement outputs to quantify the quality of a peening process in surface enhancement operation of metal parts. In practice, these parameters can only be measured offline upon process completion, which are not suitable for online tracking and operation. Instead, shot stream velocity can be used as a real-time monitoring parameter to bridge operational inputs to the outputs. As such, a robust and accurate shot stream velocity model is needed for real-time tracking. In this study, we propose a blended practical model for shot stream velocity to address the issues. The model is constructed using regression algorithm based on the blended candidate functions, which are developed from experimental data and nature of the particle-air flow inside the system. Obtained model is validated against experimental data for different conditions. Calculated velocities are in good agreement with the measurements. In addition, applications of the model in predicting the shot stream velocity for different peen types, different peening intensities and coverages. The obtained results are comparable to the measurement data. Furthermore, a single-input and single-output model-based control is developed from proposed shot stream velocity model. The developed control system is robust, accurate and reliable. It implies that the developed model can be used to provide necessary information as well as in optimal process control development to improve and accelerate the peening processes to reduce cost and time of actual productions.
\end{abstract}

Keywords: Shot peening; Regression method; Shot stream velocity; Peening intensity; Model predictive control

\section{Introduction}

Among surface enhancement techniques, shot peening is a highly efficient and relative low-cost method, which is widely used in aerospace [1] and automotive industries [2] to improve the fatigue life of metallic components [3]. In particular, compressive residual stresses near the surface are created by multiple impacts of high-speed spherical shots, thereby contributing to the work hardening of the 
surface and in turn improving the fatigue life of the component. A practical peening operation often requires many experimental trials to build an Almen system for process guidance [4-6]. Performing experimental trials can be very time consuming, labor intensive and lead to material wastage as well. In addition, quality of a peened surface often relies on measurement value of intensity and coverage, which are strongly dependent on input peening parameters (e.g., inlet air pressure, media flowrate, impact velocity and angle, component material properties, peen size and type, number of impacts, stand-off distance, etc.) [7-10]. For quantification, both intensity and coverage are statistical parameters, which can only be measured after peening operation by using Almen system [5-7,11-13] and image processing methods [14-16], respectively. To reduce the labor, cost, time, and material wastage of repetitive constructing Almen system, a robust and accurate model for practical peening operation has been attracted for practical operations. Take for examples of evaluation of an optimal operating condition for a pre-defined intensity and coverage, calculation of an intensity and/or coverage from a setting operational condition, online process monitoring, and real-time feedback control, etc.

There are two main general models widely used in the shot peening applications, namely firstprinciple model and data model. The first principle model is mainly employed to investigate physical insights, peening mechanism, and effects of input parameters on outputs of shot peening processes at high resolution, etc. For examples, Tu et al. [17] employed a sequential discrete element model (DEM) - finite element model (FEM) coupling method to study residual stress and roughness under the effects of process parameters. Zhang [18] performed FEM simulations to study the residual stress distribution and surface tribological behavior. Gariépy et al. [19] studied the potential influence of impact velocity variability on residual stress state and surface roughness using FEM and Monte Carlo simulations. Nguyen et al. [20] modelled air-peen flow using Eulerian-Lagrangian approaches to predict peening coverage area. And Lin et al. [21] established a combination model of multiple shots model and dislocation density using constitutive equations to study the effects of peening velocity, coverage, and double peening on surface integrity in term of residual stress, surface roughness, and dislocation cell size. Whilst data model is mainly applied to study on responses of the output(s) or interested parameter(s) to any variation of the dependent operational parameters to support and improve peening operation, process monitoring, and feedback control. Such as, Miao et al. [22] developed an analytical model for shot peening process to monitor Almen intensity and residual stress distribution for Almen strips under different operating conditions (e.g., shot type, size, velocity, and angle, etc.). Seddik et al. [23] employed response surface methodology coupled with finite element analysis to study the effects of shot velocity, shot diameter, exposure time and their interaction on the fatigue performance of the components for designer in shot peening parameter optimization. Nam et al. [24] used the response surface methodology for peening process optimization of aircraft structure part under the effects of nozzle distance, pressure, impact angle, and exposure time on the Almen intensity and coverage using quadratic approximations. Wang et al. [25] employed the response 
surface methodology to optimize the response variables (maximum compressive residual stress, the depth of residual stress field, and concentration factor) with dependent variable of shot velocity, shot diameter and coverage ratio based on the obtained FEM results using quadratic polynomial function. Unal [26] performed optimizations for shot peening parameters using response surface methodology by selecting the surface roughness and hardness as the responses to classify the shot peening processes. In addition, Kirk [27] performed curve fitting for shot peening data analysis. In general, the numerical methods based the first principle model are often performed in 3-dimensional simulations, which require huge computational resources and time consuming. It is often not suitable for real-time monitoring and/or feedback control. And most of the existing developed data models are often relied on polynomial curve fittings (linear, quadratic, cubic polynomial approximation, etc.), and did not account for physical characteristics of the process. As such, the obtained data models often have no relevant physical meaning or even invalid operating conditions. Thus, an incorporation of nature and characteristics of the particle-air flow into the data model is vitally important to obtain a robust and accurate data model for output prediction, online tracking, and real-time feedback control system.

In reality, both the intensity and coverage cannot be tracked or measured during peening operation. Therefore, an alternative real-time measurable parameter/variable is requested for both process monitoring and optimal feedback control applications. Among feasible variables, shot stream velocity upon impact considered as a great candidate for real-time tracking and feedback control because the shot stream velocity can play a role of a bridge to link operational inputs to peening intensity and/or coverage [28-30]. Currently, both ShotMeter [29, 31-33] and high-speed camera [29, 34-36] are widely used to measure shot stream velocity in shot peening application. The high-speed camera however often requires an open and large space for installation. Using high-speed camera also often requires an external software that takes time for image-processing to evaluate the shot stream velocity; therefore, it might not suitable for real-time monitoring or feedback control. In addition, the highspeed camera also requires special safety requirements to protect the camera. Whist, the ShotMeter uses a simple method of particle illumination to measure the shot stream velocity and does not require special safety features to protect this device. In which, two electro-optical sensors with a fixed spacing measures the shot stream as they travel toward downstream from the shot peening nozzle exit. The signals from these two sensor are compared to obtain a phase shift that is used to evaluate the shot stream velocity with an accuracy of about $1 \%$ [37]. The latest version of ShotMeter is a low-cost \& rugged technology, which enables real-time measurement of shot stream velocity for process development as well as troubleshooting activities. With integrated software, it allows the ShotMeter to continuously record data as a function of time for easy retrieval using spreadsheet [38]. Thus, with its great advantages, the ShotMeter is utilized in this study to record the shot stream velocity for model development, as well as online tracking later. 
Thus, in this study, a practical shot-stream velocity model is developed using regression algorithm, which is based on experimental data and candidate functions of separated operational inputs. For data collection, the averaged shot stream velocity is measured at a small region upon the impact location using ShotMeter for different operational inputs, while intensity data is obtained from other sets of experiments for the same input conditions. For applications, the shot stream velocity model is developed to (1) predict shot stream velocity of different peen types under different operating conditions; (2) predict peeing intensity and coverage for different operational inputs; (3) develop a closed loop optimal control system using process model. This paper is organized as the followings. Section (1) introduces purpose and objectives of this study. Section (2) describes experimental setup and data collection. Section (3) expresses the process construction of candidate functions. Section (4) demonstrates the applications of the shot stream velocity model. Finally, Section (5) concludes the contents of this paper.

\section{Experimental trials}

In actual peening operation, the both inlet air pressure and peen (or media) flowrate are dynamically manipulated to achieve target setting intensity and/or coverage. In previous study [20], we have studied the relation of shot stream velocity and peening coverage. Thus, this study only focuses on the development of shot stream velocity model to link up the inlet air pressure and media flowrate to peening intensity.

\subsection{Experimental setup}

To build the shot stream velocity model, the shot peening machine from Abrasive Engineering Singapore Lt. Co, which is shown in Fig. 1 (left), and schematic diagram of experimental setup is shown in Fig. 1 (right). In particular, a straight bore nozzle with internal diameter of $14.0 \mathrm{~mm}$, which is widely used in the industry, is used in the experimental trials. The shot types ASR 70 with averaged size of $0.1778 \mathrm{~mm}$ (or $0.007 \mathrm{inch}$ ) is utilized to measure shot stream velocity and intensity. The shot stream velocity upon the impact is experimentally measured using ShotMeter, while Almen system with saturation curve is used to evaluate measurement intensity. Two piezoresistive pressure sensors from KISTLER are mounted at inlet (before shot injected point) and on the nozzle to measure the air pressure at inlet $\left(P_{\text {in }}\right)$ and outlet $\left(P_{\text {out }}\right)$, respectively. The pressure difference of the two sensors is determined as a pressure loss along the system and energy transferring to the peens. To hold the strips during the tests, an Almen strip holder is designed to fix up to 8 Almen strips on both sides ( 4 strips for each side) for each test (see Fig. 2).

In this study, two similar sets of experiments with the same operating conditions are performed for to measure shot stream velocity and peening intensity, separately. For each set of trials, five different media flowrates (of 1, 2, 3, 4, and $5 \mathrm{~kg} / \mathrm{min}$ ) are set for each value of four inlet air pressures $(20,30$ 44 , and 54 psi or $(1.379,2.068,3.034$, and 3.723 bars $))$ to form 20 experimental peening conditions. 
The values of air pressure and media flowrate are selected within the operational windows of current shot peening machine. The standoff distance and impingement angle are chosen from actual operation at $120 \mathrm{~mm}$ and $70^{\circ}$, respectively.
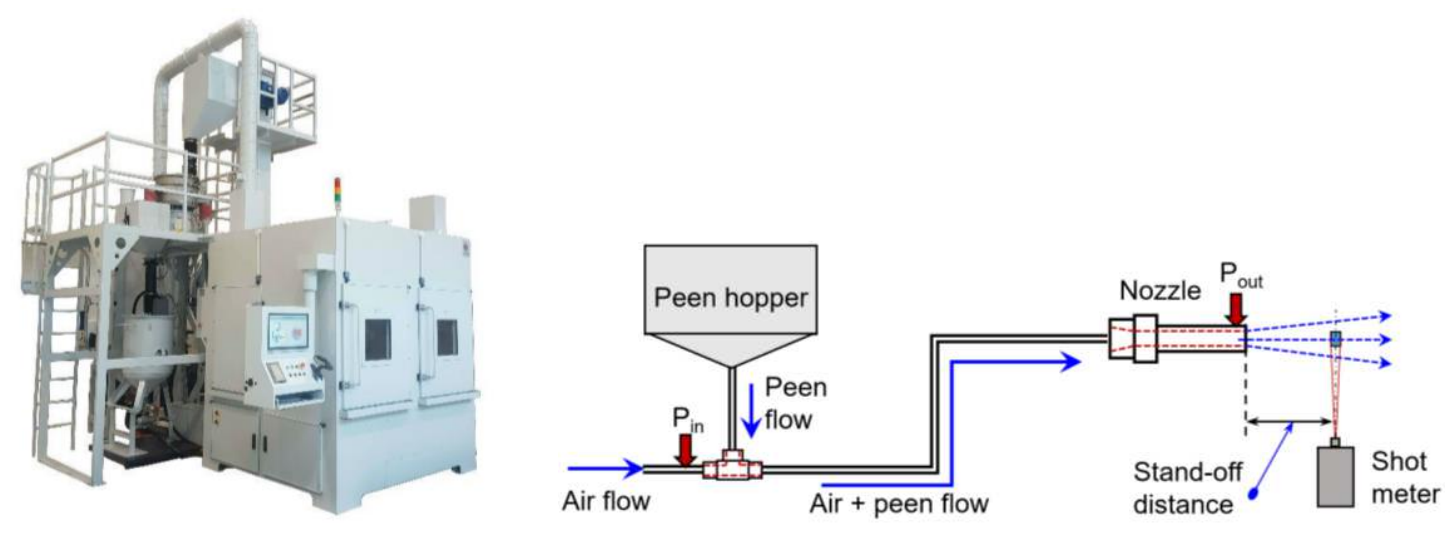

Fig. 1: Abrasive Engineering shot peening machine (left) and Schematic diagram of experimental setup with mounted sensor location and ShotMeter (right).

For shot stream velocity measurement, the experimental setup is shown in Fig. 1 (right), where ShotMeter focuses on a small region upon the impaction with a standoff distance of $\mathrm{S}=120 \mathrm{~mm}$ from nozzle exit. Location of the ShotMeter is determined by a laser source integrated inside the ShotMeter, which is turned on to detect distance from ShotMeter to selected measurement area automatically for accurate measurement results. The laser is turned off after fixing the location of ShotMeter. The ShotMeter uses two electro optical sensors with known spacing sense particles in the selected frame to evaluate the shot stream velocity. The integrated sensors inside the ShotMeter receive signal as peens pass through; these signals are compared and the resulting phase shift is used to calculate shot velocity with an accuracy of about $1.0 \%$. ShotMeter is also calibrated and setup to ensure that measurement results are accurate and only measure the incoming shots, while shot interferences or rebounding are eliminated during measurement process. It should be noted that the ShotMeter often requires an unobstructed stream of media during the measurement process.

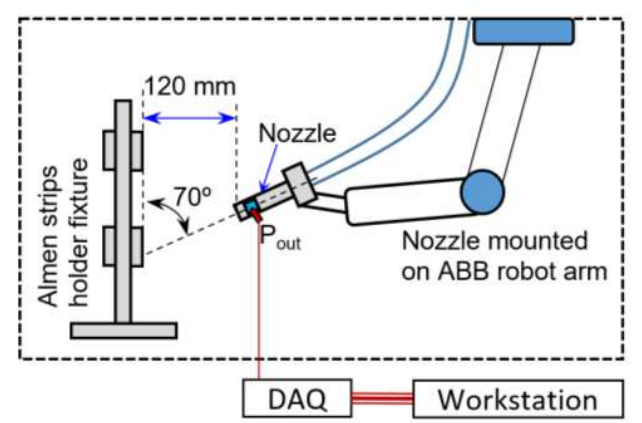

Fig. 2: Experimental setup for peening intensity measurement 
For intensity measurement, the shot stream is directly shot on the Almen strips from stand-off distance of $120 \mathrm{~mm}$ and peening angle of $70^{\circ}$ for measuring intensity. The system is calibrated to ensure that the settings are similar to the previous experimental set. To ensure the model is relevant and consistent, the operating conditions are assumed to be valid as both pressure and mass flow rate did not vary drastically (e.g., $\sim \pm 1$ psi of pressure and $\pm 0.2 \mathrm{~kg} / \mathrm{min}$ of mass flow rate) in both experimental sets. The measurement values of arc height for each operating condition are used to construct a saturation curve to determine peening intensity and saturation time. Normally, a minimum of four points with four corresponding exposure times is required to plot a saturation curve. In addition, each corresponding intensity value is experimentally repeated for at least 4 times with tolerance of $\pm 0.02 \mathrm{mmA}$ to ensure the measurements are accurate and repeatable. The experimental setup is shown in Fig. 2.

\subsection{Shot stream velocity measurement result and discussion}

For shot stream velocity measurement, each experiment is performed for about 120 seconds, while spherical shots are released for a period of about 80 seconds. ShotMeter measures and saves measurement data at every 0.1 seconds. Measurement data of three typical cases are shown in Fig. 3. Obtained results shows that the shot stream velocity is higher for a higher inlet air pressure for the same media flowrate. Inversely, the shot stream velocity is lower for higher media flowrate for the same inlet air pressure. The measurement results are more accurate and stable when the media flowrate is higher, and inversely. After reaching each stable state, the shot stream velocity attains a constant value, which is shown by the dashed lines in Fig. 3. As such, the averaged value of the shot stream velocity for each operating condition is used in the later analysis for model development.

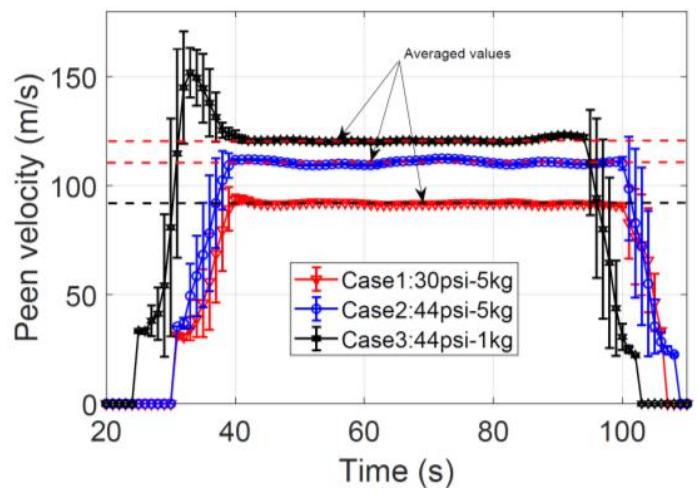

Fig. 3: Measurement shot stream velocity for different operating conditions.

The averaged measurement data of shot stream velocity for all cases are shown in Fig. 4. Each averaged value is evaluated from four times of repeating experiments for each operating condition. The obtained results clearly show that the averaged shot stream velocity increases with the increase in air pressure, and decreases with the increase in media flowrate. Physically, for the same peening system and media flowrate, a higher inlet air pressure can bring a higher airflow velocity inside system and directly provide a higher energy transferred from the air stream to media, which leads to a higher 
shot stream velocity. For a similar inlet air pressure, the momentum energy transferred from airflow to individual shot particle is lesser as number of shot particles increases, as such the averaged shot stream velocity is lower. The obtained results also show that the shot stream velocity is more sensitive to the inlet air pressure than media flowrate. In addition, the measurement data also indicates that the shot stream velocity slightly fluctuates at the region of high inlet air pressure. The fluctuation is caused by some factors such as the media flow control valve fluctuation, calibration drift of pressure valve and compressor stability, shockwave formation and propagation, etc.

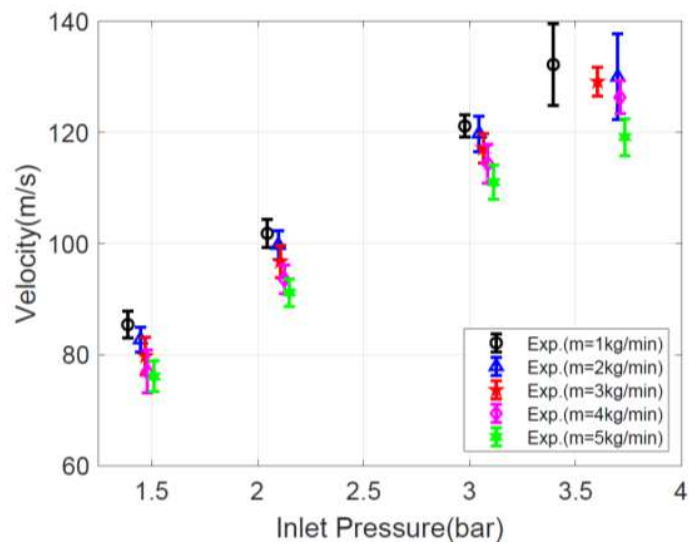

Fig. 4: Averaged shot stream velocity for different media flowrate and inlet air pressure.

\subsection{Peening intensity measurement result}

To quantify the peening intensity, an Almen gage is employed to measure the arc height of the Almen strip before and after peening process to determine the change in arc height caused by the peening process. Fig. 5(a) shows the Almen gage for measuring arc height, while Fig. 5(b) represents the arc height information of the four peened Almen strips. Normally, a minimum four points of arc heights at different peening times are required for plotting a saturation curve to determine a peening intensity value and exposure time. Fig. 5(c) shows a typical saturation curve with information of intensity and exposure time.

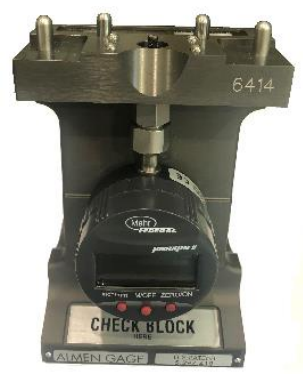

(a)

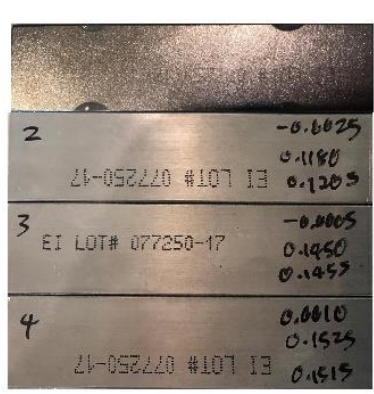

(b)

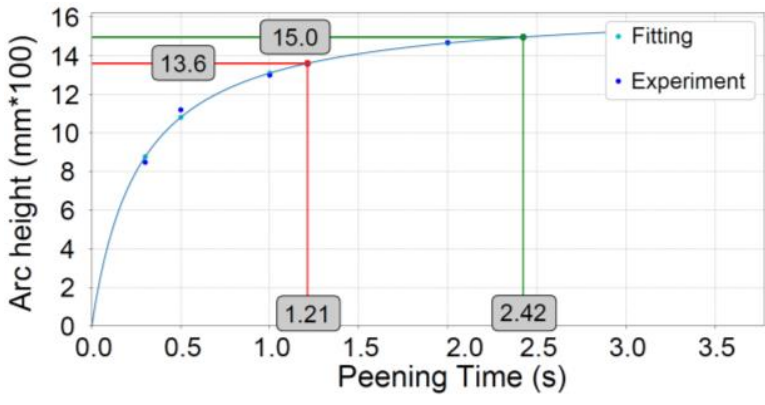

(c)

Fig. 5: Measurement peening intensity: (a) Almen gage for measuring the arc height to plot the saturation curve and measurement intensity, (b) peened Almen strips with before and after arc height information, and (c) Plotted saturation curve with determined intensity $(I=0.136 \mathrm{mmA})$ and exposure time $(\mathrm{T} 1=1.21 \mathrm{~s})$. 
In these experimental trials, each operating condition is experimentally repeated for four times to ensure that all variation falls within the industrial threshold of $\pm 0.02 \mathrm{mmA}$. Each averaged value is evaluated from four measurement values for each operating condition. Fig. 6 shows averaged measurement values of intensity for different operational conditions. Generally, the obtained results show that the peening intensity is greater as the inlet air pressure is higher, while the peening intensity is smaller as the media flowrate is higher. As the peening intensity represents the kinetic energy of the peens transferred to the substrate, which is proportional to quadratic relation of peen velocity $\left(m v^{2} / 2\right)$ and linear form of media flowrate. As mentioned in previous subsection that the shot stream velocity is higher as the inlet air pressure is higher, while it is lower as media flowrate is higher. And, in fact, the change of shot stream velocity is much greater than the change of media flowrate that explain why the peening intensity is more sensitive to the inlet air pressure than the media flowrate.

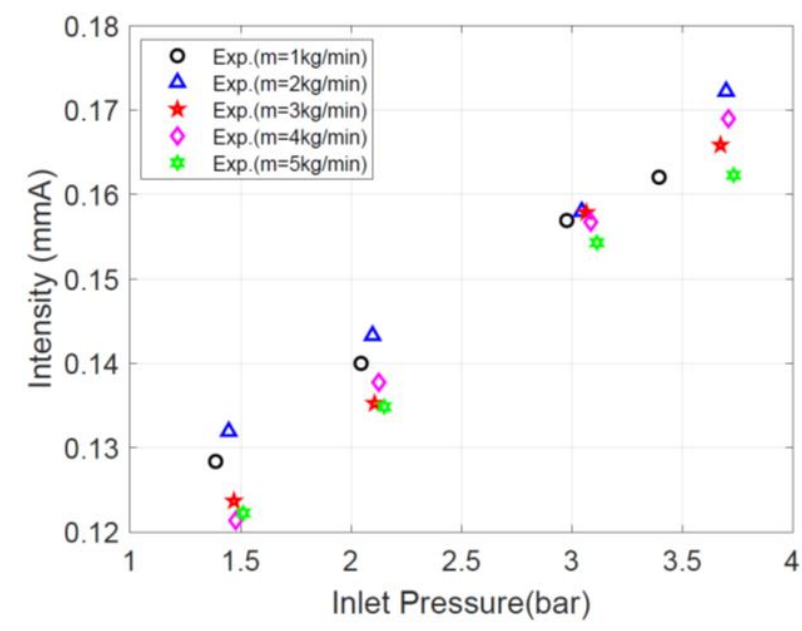

Fig. 6: Averaged measurement values of peening intensity for different operating conditions of inlet air pressure and media flowrate.

\section{Shot stream velocity model development}

As mentioned in previous section that the inlet air pressure and media flowrate are two control variables, which are manipulated to attain the target setting intensity and/or coverage. In this section, the shot stream velocity model is developed to link the inlet operational variables of inlet air pressure and media flowrate to the intermediate variable of shot stream velocity for process monitoring and control development, as well as other applications. The velocity model is developed using regression method based on candidate functions, while the candidate functions are constructed based on experimental data and physical insights of process flow nature.

\subsection{Development of candidate functions for library construction}

To build an accurate and suitable candidate functional library, we first analyze the obtained experimental data to gain understanding physical insights of the peening process as well as dependent parameters. In fact, the dependent parameters include the inlet air pressure, media flowrate, pressure 
loss inside the system, piping system, nozzle geometry configuration, shot type, stand-off distance, and impinging angle, etc. However, in this study, we only focus on main parameters of inlet air pressure, media flowrate and pressure lost, while other parameters are worth to consider in other study in a future plan. Followings are the details of analysis and candidate functions for functional library construction.

\subsubsection{Candidate function of shot stream velocity for inlet air pressure}

To study relation of inlet air pressure and shot stream velocity, a pressure sensor mounted at a location on the air pipe just before the peen-released point is used to record inlet air pressure, while the ShotMeter is employed to measure shot stream velocity upon impact region. The measurement results show that the increase of inlet air pressure leads to an increase of the shot stream velocity exponentially. In fact, the shot stream velocity only reaches to a maximum value although the inlet air pressure keeps increasing. It can be explained that the increase of the inlet air pressure results an increase in airflow velocity from subsonic to supersonic. However, the airflow velocity also reaches to a certain maximum value due to compressibility effects, as the result the shot stream velocity can only reach to a certain maximum value. Mathematically, a chosen candidate function must be valid that the shot stream velocity will be zero as inlet air pressure $\left(p_{\text {inlet }}\right)$ is zero, and the velocity reaches to a maximum value as inlet air pressure reaches to a certain value or higher as nature of the flow in the system. Thus, a candidate function with the form of $f_{1}(p)=P_{0}\left(1-\exp \left(-P_{1} * p_{\text {inlet }}\right)\right)$ satisfies the requirements. In this expression, $P_{0}$ and $P_{1}$ are the model parameters, while $p_{\text {inlet }}$ is inlet air pressure. Fig. 7 shows the fitting of the above candidate function of the shot stream velocity as the function of the inlet air pressure for different media flowrates. It can be seen that the chosen function can fit very well with the experimental data. Thus, in this study, this function is chosen as a candidate function for shot stream velocity versus inlet air pressure. This function is stored in the library for blended model development later.

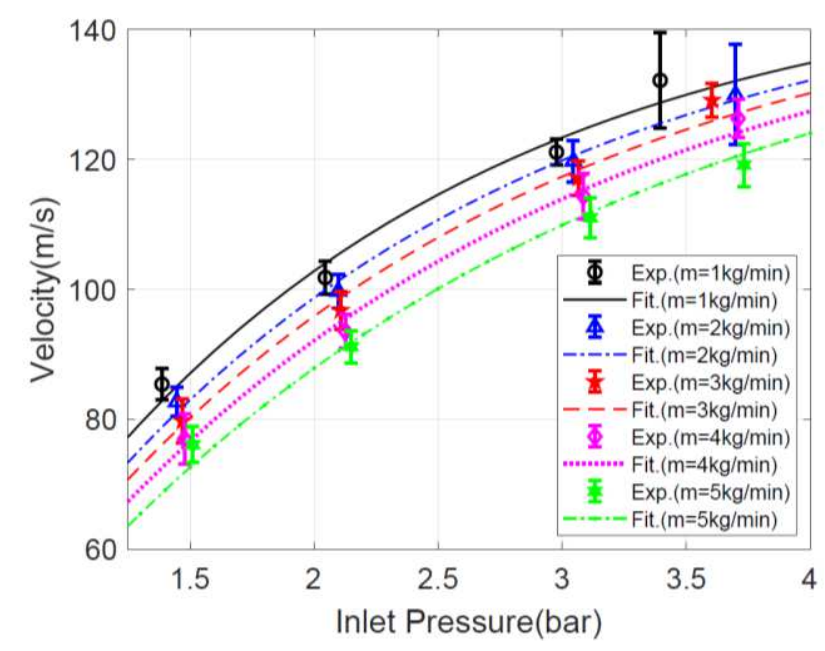

Fig. 7: Averaged shot stream velocity vs. inlet pressure for ASR 70 peen type using exponential curve fitting of $\left(f_{1}=P_{0}\left(1-\exp \left(-P_{1} * p_{\text {inlet }}\right)\right)\right)$. 


\subsubsection{Candidate function of shot stream velocity for pressure drop}

To gain understanding on the relation of the shot stream velocity and the pressure loss, a pressure sensor is placed at the inlet and another pressure sensor are mounted near nozzle exit (see Fig. 1) to measure the pressure loss along peening system, $\Delta p=p_{\text {intlet }}-p_{\text {outlet }}$. As mentioned before that the momentum transferred from airflow to the peens is one of the factor among others (e.g., the turbulence, friction, and piping system, etc.) that causes pressure loss inside the peening system. The obtained results show that an increase in pressure loss can lead to an increase in shot velocity (refer to Fig. 8). We have tried different fitting functions, however, we found that the exponential function is the best fit for the measurement data. Fig. 8 shows the plot of averaged measurement shot stream velocity against the pressure loss $(\Delta p)$ using the proposed function of $f_{2}(\Delta p)=f\left(\frac{1}{\exp \left(P_{2} * \Delta p\right)}\right)$. In this function, $P_{2}$ is a model parameter. The plot shows that the selected candidate function can be fit well for the pressure loss and average shot stream velocity. Thus, in this study, this $f_{2}(\Delta p)$ candidate function is also selected and added to the function library for blended model development later.

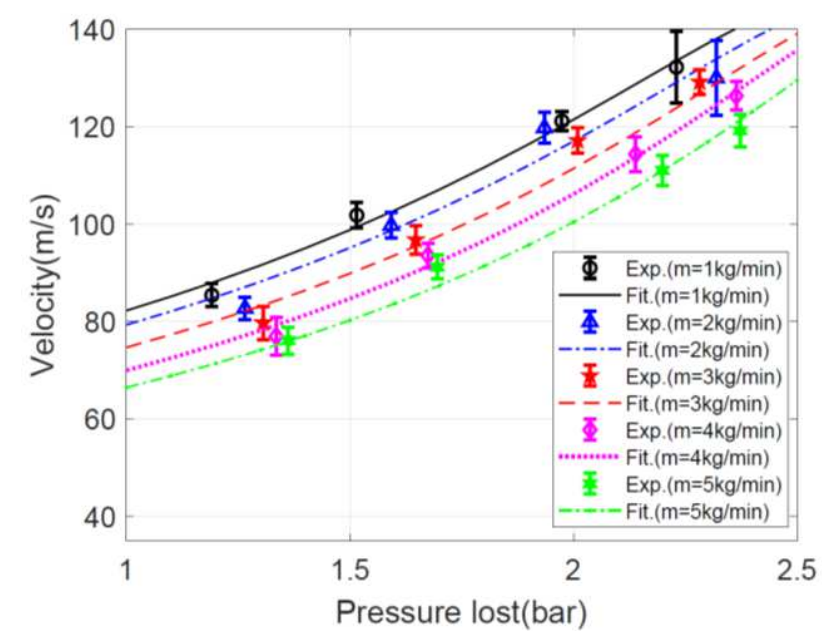

Fig. 8: Averaged shot stream velocity plots against the pressure drop for peen type of ASR 70 using exponential fitting function.

\subsubsection{Candidate function of shot stream velocity for media flow rate}

Physically, to ensure that the model is valid and consistent, the model has to satisfy some constraints of particle-air flow nature; e.g, for a certain inlet air pressure, the stream shot velocity must be zero as the media flowrate increases to a certain maximum value, while the shot stream velocity achieves a maximum value as the media flowrate reduces to a certain minimum value. A mathematical model in the form of $f_{3}(m)=P_{3}\left(\frac{1}{\exp \left(P_{4}+P_{5} * m+P_{6} * m^{2}\right)}\right)$ is derived to satisfy the above contrainsts and fit well with the measurment data. In this function, $P_{3}, P_{4}, P_{5}$ and $P_{6}$ are model parameters. Fig. 9 shows the plot of shot stream velocity against the media flowrate for certain inlet air pressure values using the derived fitting function. It is clear that the chosen candidate function can fit well with the experimental 
data. In addition, the plot also shows that the change of the media flowrate does not significantly influence the change of the shot stream velocity as compared to the change inlet air pressure. In another word, the shot stream velocity is more sensitive to the change of the inlet air pressure compare to the media flowrate. It is consistent with the analysis in previous section. Thus, similarly, this candidate function is also chosen and stored in the candidate functional library for model development.

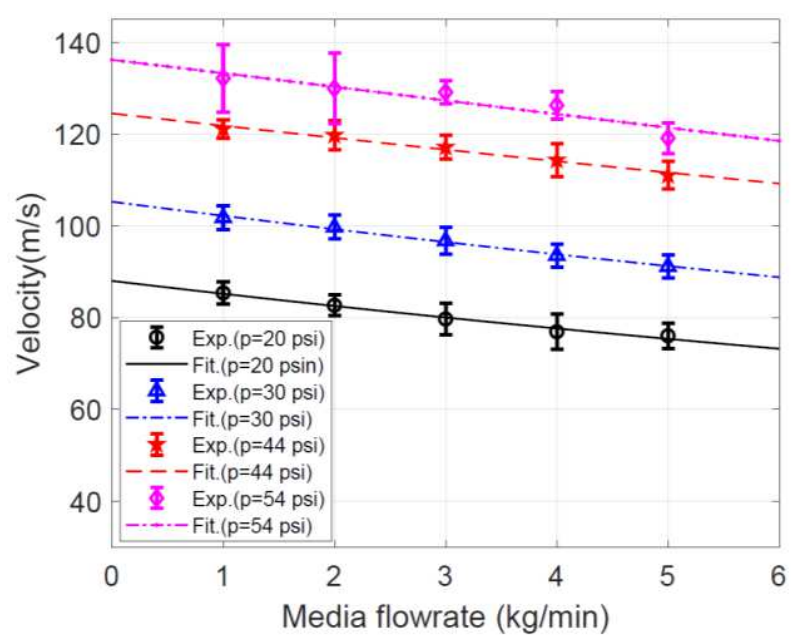

Fig. 9: Averaged shot stream velocity plots against peen mass flowrate for ASR 70 peen type using fitting function.

\subsection{Shot stream velocity model development with regression method}

In this subsection, the shot stream velocity model is developed using regression method based on the blended candidate functions that developed in previous section. The regression method is widely used in mathematical and statistical representation for modeling, analyzing, and optimizing a process where the outputs response to the change of input variables [39-42].

\subsubsection{Regression method for sparse nonlinear system}

Theoretically, a dynamical model can be expressed in a form of desired parameters and inputs variables $X=\left[x_{1}, x_{2}, x_{3}, \ldots, x_{n}\right]$ as

$$
y=f\left(\theta_{1}, \theta_{2}, \theta_{3}, \ldots, \theta_{m} ; x_{1}, x_{2}, x_{3}, \ldots, x_{n}\right) .
$$

In this expression, $\theta_{1}, \theta_{2}, \theta_{3}, \ldots, \theta_{m}$ are model parameters of the process system. In this study, the considered variables include inlet air pressure, peen media flowrate and pressure loss. Solving for model parameter in equation (1) often employs regression algorithm with measurement data of different operating conditions and solve them directly. However, in this study, we employ sparse regression to identify a spare $\boldsymbol{\Xi}=\left[\theta_{1}, \theta_{2}, \theta_{3}, \ldots, \theta_{m}\right]^{T}$ corresponding to the fewest nonlinearities in stored functional library to give a better model performance with

$$
\xi_{k}=\underbrace{\operatorname{argmin}}_{x} \frac{1}{2}\left\|V_{k}-\hat{\xi}_{k} \theta^{T}(X)\right\|_{2}^{2}+\lambda\left\|\hat{\xi}_{k}\right\|_{1}
$$


The term $\left\|\hat{\xi}_{k}\right\|_{1}$ term promotes sparsity in the coefficient vector $\xi$. And $V_{k}$ is measurement shot stream velocity or intensity. This optimization can be solved using the sequentially threshold least squares procedures as in the following algorithm:

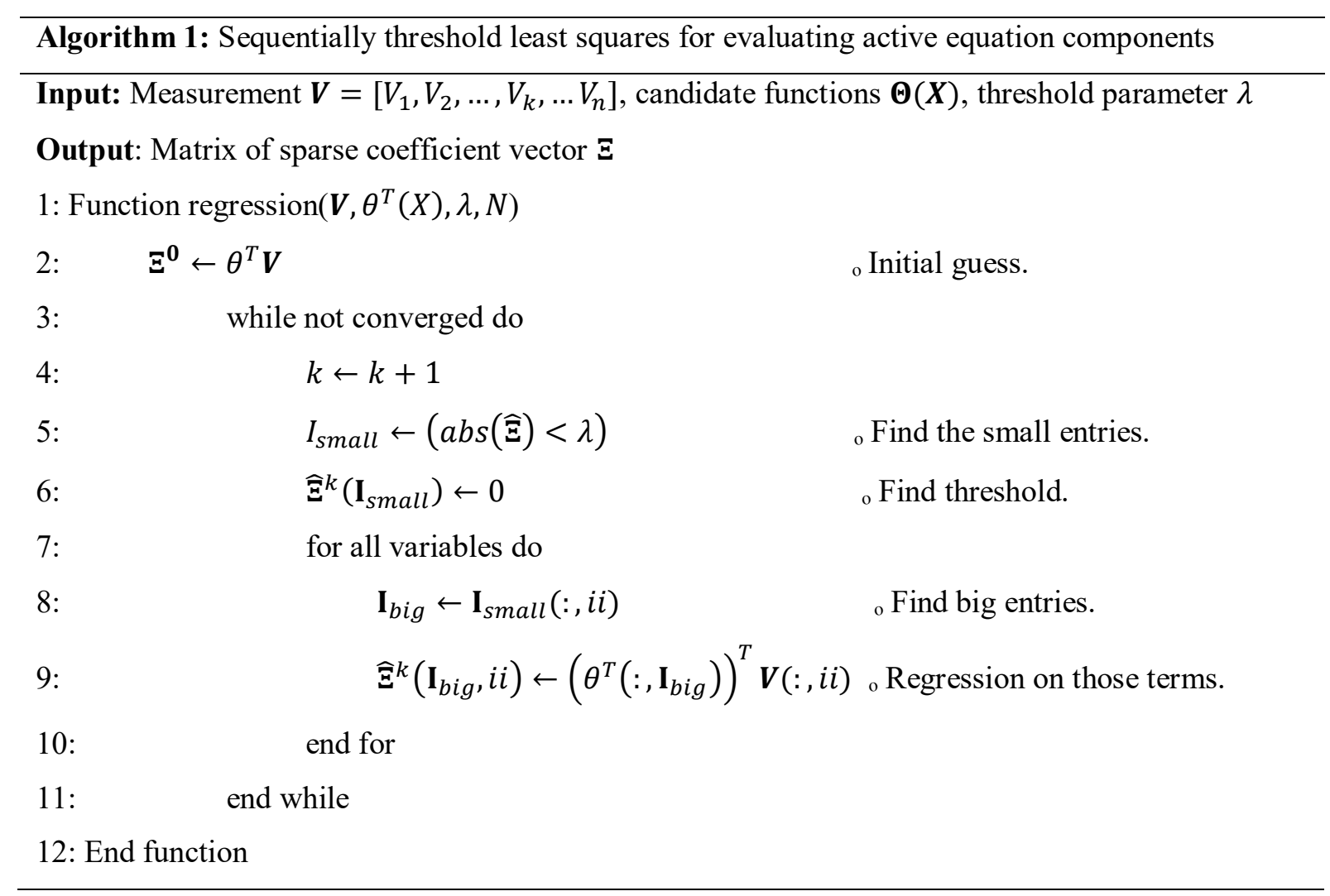

\subsubsection{Development of the blended shot stream velocity model}

Besides candidate functions and physical insights mentioned in previous subsections, the final blended form of the shot stream velocity must also be valid for the following physic laws. (1) The shot stream velocity must be zeros when the inlet air pressure is zero. (2) The shot stream velocity reaches a certain maximum velocity for a certain or higher inlet air pressure due to the effect of the compressibility. (3) For a certain inlet air pressure, the shot stream velocity must be zeros as media flowrate reaches to a certain value or higher. (4) The shot stream velocity attains maximum value as media flowrate reduces to a certain small value (near to zero). (5) Finally, the pressure loss $(\Delta p)$ along the peening system must always be smaller than inlet air pressure. The Eqn. (3) is derived from the three selected candidate functions and satisfies the above 5 constraints, can be expressed as

$f(p, \Delta p, m)=\frac{1}{\sqrt{S}} * A *\left(1-\exp \left(\frac{-B * p}{C * \Delta p+D * m+E * m^{2}}\right)\right)$.

In this formulation, $f(p, \Delta p, m)$ is shot stream velocity upon impact region, while $p, \Delta p$, and $m$ are inlet air pressure, pressure loss along the system, and media flowrate, respectively. Moreover, in this study, we introduce that $S$ is a constant parameter representing for peen type (e.g., ASR 70 or $S=70$ ). Coefficient $A$ is system parameter that represents for typical shot peening machine. A might be different for other machines. Parameter $B$ is a coefficient for inlet air pressure. Parameter $C$ describes 
a coefficient for pressure loss along the peening system. In addition, $D$ and $E$ are parameters related to convection and diffusion energy transfer to the shot peens, respectively.

These coefficients and parameters are evaluated using proposed regression method with measurement experimental data as mentioned in previous subsection. In this study, the coefficients $(A, B, C, D$ and $E)$ are $1250,1.0,1.1,0.015$ and 0.00015 , respectively. The root means square fit of this regression method is 0.9687 , and the maximum root mean squared error is about $7 \mathrm{~m} / \mathrm{s}$ (about $<5 \%$ ). The obtained blended model and the residual fit are presented in Fig. 10. It also can see that the developed model can accurately predict the shot stream velocity for any given set of operational input of inlet pressure and media flowrate with measured pressure loss. In addition, recall that the shot stream velocity is more sensitive to the inlet air pressure than the media flowrate. It implies that it is possible to control the peen velocity by adjusting the inlet air pressure, while it is difficult to success by manipulating the peen mass flowrate.
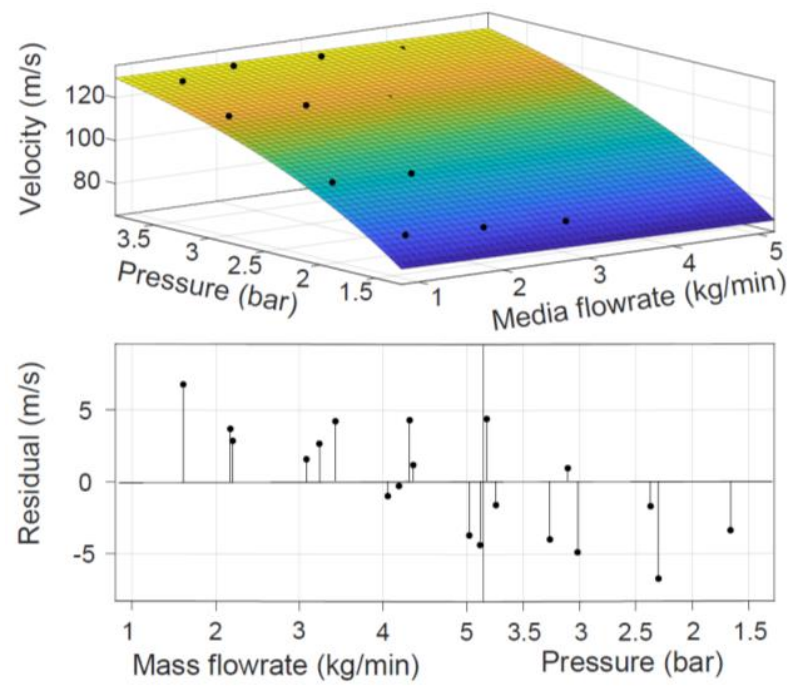

Fig. 10: Comparison of blended model with experimental data (upper) and the residual fits (lower).

\section{Applications of developed model of shot stream velocity}

In this section, the developed model of shot stream velocity is applied to (1) predict shot stream velocity of different peen type for different operating conditions, (2) predict peening intensity for a given operational inputs, and (3) develop optimal feedback control system for automated shot peening machine. Followings are the details.

\subsection{Prediction of shot stream velocity for other shot type}

In this subsection, developed model is applied to predict the averaged shot stream velocity of other peen type (ASR 230) for different operating conditions within the same shot peening machine. Here, the Eqn. (3) is employed to predict shot stream velocity of ASR 230 peen type and benchmarked with the measurement data. In particular, the system parameter $(A)$, pressure coefficient $(B)$ and pressure 
loss coefficient $(C)$ are kept similar to the ASR 70 peen type, which are 1250, 1.0 and 1.1, respectively, while the peen parameter $(S)$ is changed from 70 to 230 . The convection coefficient $(D)$ and diffusion coefficient $(E)$ are increased proportionally to the peen size, which are determined as $D=\left(\frac{230}{70}\right) * 0.015=0.049285$ and $E=\left(\frac{230}{70}\right) * 0.00015=0.00049285$, respectively. The predicted results are compared with experimental data of the same operational conditions to benchmark for the model accuracy as shown in shown in Fig. 11. It can be seen that the prediction results are in good agreement with experimental data for all operating conditions. It implies that the developed model can be used to predict shot stream velocity of different peening types for different operating conditions of the same shot peening machine by only changing peen size and its ratios. Furthermore, it can be applied to predict shot stream velocity of other shot peening machine by choosing a suitable system parameter $(A)$ and peen parameters, accordingly.

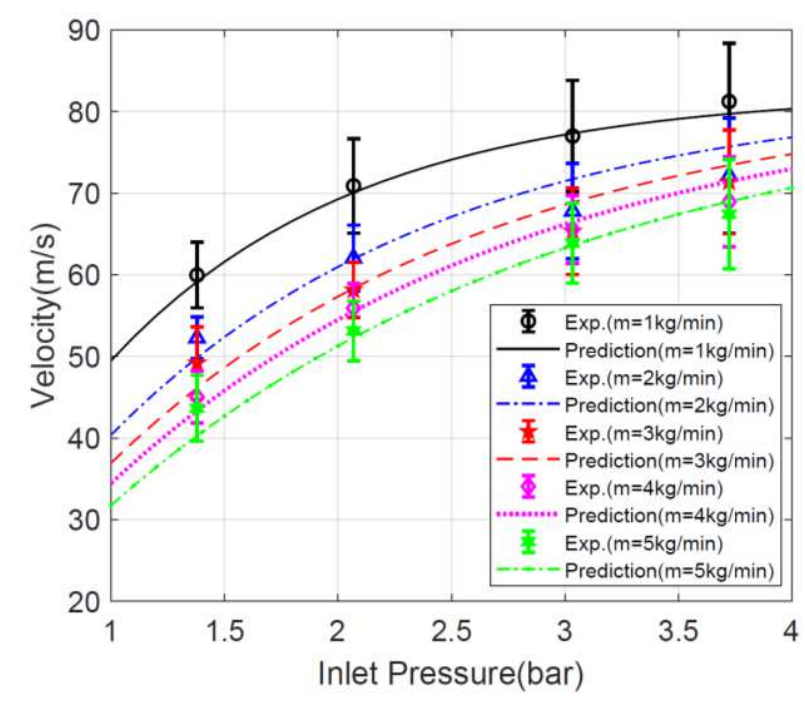

Fig. 11: Comparison of predicted shot stream velocity and the experimental data of ASR 230 peen type for different operational input conditions.

\subsection{Prediction of peening intensity for different peen types}

In this subsection, the shot stream velocity developed in Eqn. (3) with relevant parameters is used to predict peening coverage and intensity for a given peen type and operating conditions. In particular, for peening coverage, the impact velocity of the shot is used to evaluate the peen work potential $\left(W_{p}=\right.$ $\left.\pi D^{3} \rho \mathrm{v}_{p}{ }^{2} /\left(12 \times 10^{6}\right)\right)$ for indented diameter evaluation [8, 15], which is then applied to compute coverage factor $(\mathrm{K})$, and coverage area using $C(\%)=100(1-\exp (-K * t))$. Nguyen et al. [20] used shot velocity at impact to calculate single dimple area using $a=\left(E_{c} * d_{p}^{2} * \sqrt{\rho} * \mathrm{v}_{p} / \sin \theta\right) / \sqrt{B}$. The formula can be applied to different peen sizes and component materials. For coverage area, multiple impacts and overlapping indentations are accounted in the prediction model as $C(\%)=100(1-$ $\left.\exp \left(-\sum_{i=1}^{N} a_{i} / A\right)\right)$. It is clear that the developed model of shot stream velocity can be used to predict 
peening coverage area for known-operational inputs. However, this study only focuses on intensity, thus, details of coverage prediction is not shown here.

For peening intensity, which is often represented by kinetic energy transferred from shot stream to material substrate, which is proportional to the shot stream velocity and media flowrate. The intensity can be evaluated using the analytical formulation as in the following form $[8,15]$ :

$$
I\left(v_{p}\right)=P_{0} * \mathrm{~S} *\left(1.0-\exp \left(-P_{2} * v_{p}\right)\right) .
$$

In which, the shot stream velocity $\left(v_{p}\right)$ is expressed in Eqn. (3). The coefficients $P_{0}$ and $P_{1}$ are 0.0031 and 0.0105 , respectively. These coefficients are much closed to 0.00366591 and 0.010482 in ref. [8, 15]. To prove for the accuracy of the model, we have performed both experiments and predictions for the same operational inputs for both ASR 70 and ASR 230 peen types. The intensity predictions use Eqn. (4) and relevant coefficients and parameters. The comparison results of the predictions and experiments for ASR 70 peen type are shown in Fig. (12 (a)), while comparisons of ASR 230 peen type are shown on Fig. 12(b). The comparison results indicate that the predicted results are in good agreement with experimental data for both peen types. The maximum error is about $\pm 0.0065 \mathrm{mmA}$, which is smaller than industry threshold of $\pm 0.02 \mathrm{mmA}$. It means that the developed model of shot stream velocity can be used to accurately predict peening intensity with given operational conditions. And it also can be used to determine an optimal set of operational input from a target setting intensity using optimization method(s) to solve for inverse problem. In another word, the optimization method can be applied for the developed model to find a suitable input operating condition from a desired intensity. As such, it can further help to reduce cost, time, labor, and wasted material for building Almen system to guide for actual practical operation.

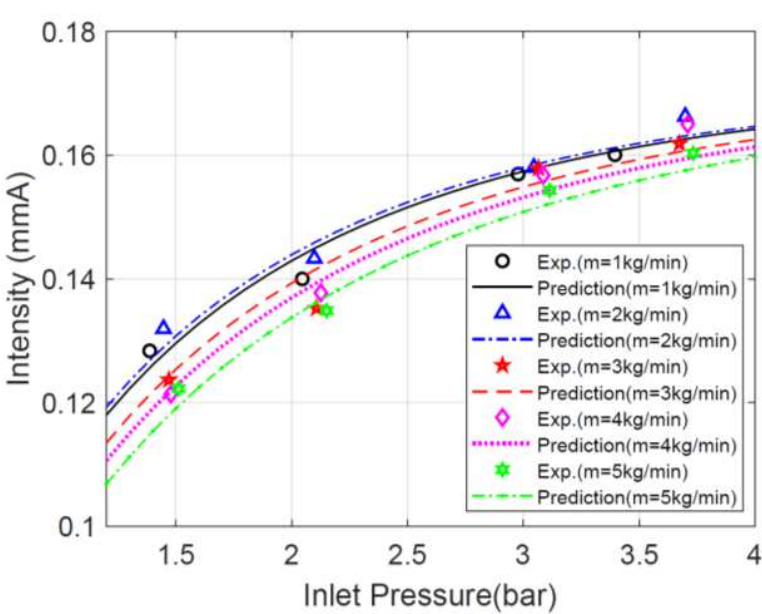

(a)

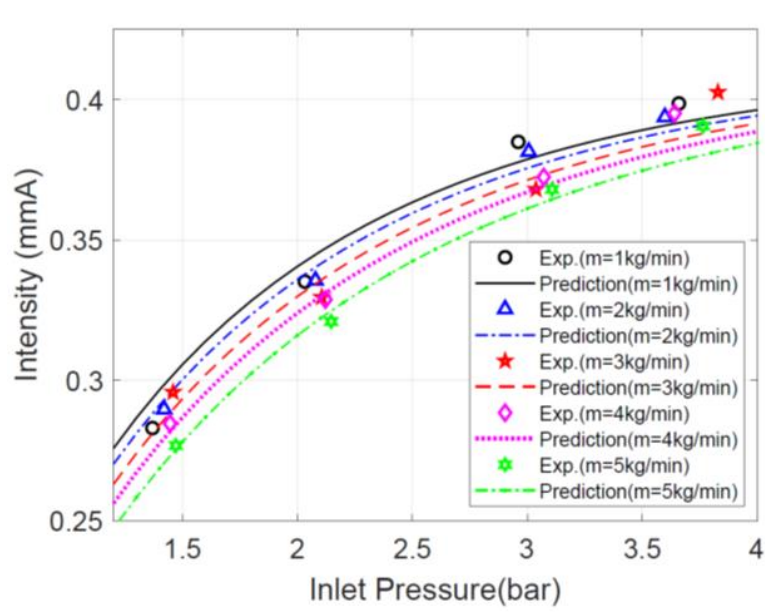

(b)

Fig. 12: Comparison of predicted intensity and experimental data for different operational input conditions: (a) ASR 70 peen type and (b) ASR 230 peen type.

\subsection{Model predictive controller design application}


As mentioned, intensity is a static parameter, which only can be measured upon the peen process completion. So that shot stream velocity is considered as an intermediate variable, which can be used to track for peening intensity in real time. Thus, in this section, the developed model of shot stream velocity is applied to develop a real-time optimal model-based control system for achieving the target setting intensity. For simplification, this study mainly focus on control system development with one control variable (inlet air pressure) and control soft-launch scenarios, while multiple inputs and onsite control is carrying on in the future development.

\subsubsection{Development of process model with control}

In this study, a model predictive control system (MPC) is developed based on feedback of shot stream velocity measurement to automatically regulate the operational inputs for attaining a target intensity. The MPC development often requires a dynamical process model, which is function of control variable(s), state variable(s), and measurement variable(s) in time. However, the current developed model is a statistical response of the shot stream velocity to the change of the inlet air pressure and media flowrate. To build dynamics process model, we use current developed model to generate shot stream velocity data from inputs of inlet air pressure for the whole range of control window with system delay time of $0.01 \mathrm{~s}$ (see Fig. 13). The delay time is obtained for current shot peening machine by performing a step change in the inlet air pressure and checking for response time of shot stream velocity at the region upon the impact.
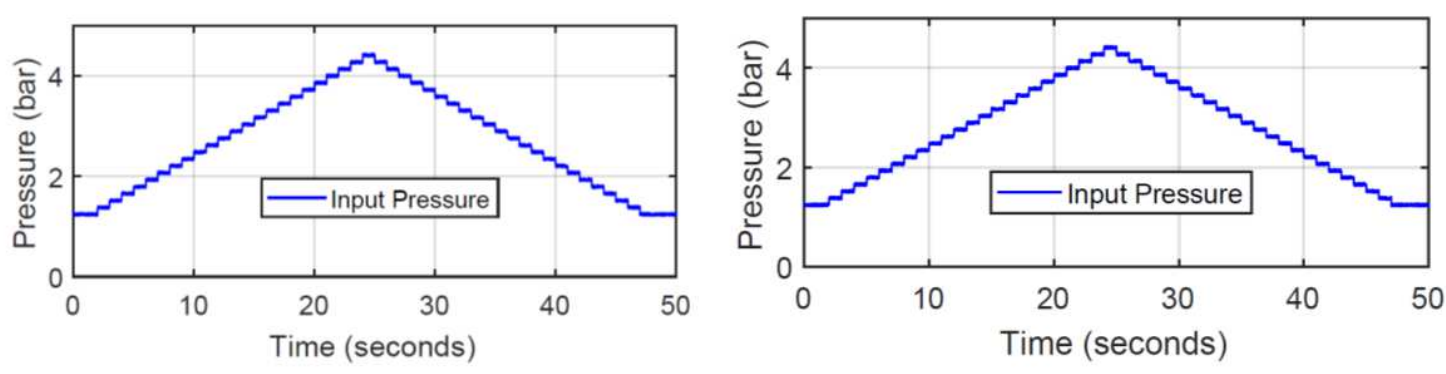

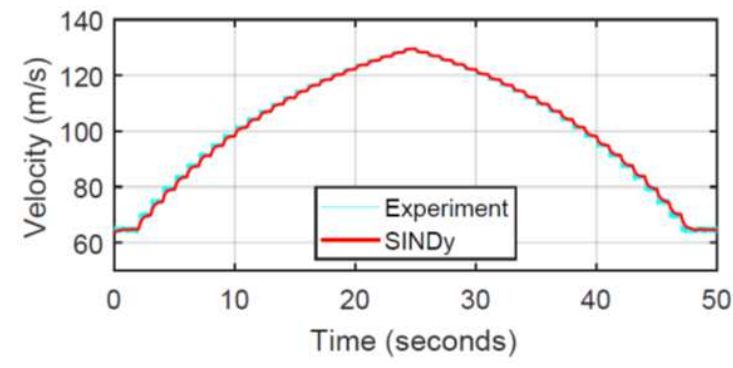

a)

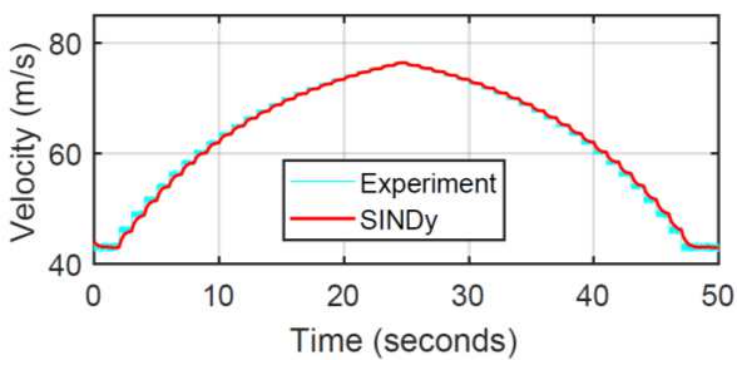

b)

Fig. 13: Comparison of shot stream velocity using SINDy process model and experimental data for the same input pressure: (a) ASR 70 peen type and (b) ASR 230 peen type.

The dynamical process model is developed based on sparse identification of nonlinear dynamical system (SINDy) algorithm with control $[41,42]$ and obtained data of both inlet air pressure and shot 
stream velocity. Following is the general form of dynamical process model obtained by SINDy algorithm:

$\dot{x}=\boldsymbol{A} x(t)+\boldsymbol{F}(x(t))+\boldsymbol{B} u(t)$.

In this expression, $x$ is state variable, while $u$ is manipulated variable. Reader can refer to reference $[41,42]$ for more details. In this study, the comparisons of the developed dynamical process model and the experimental data are shown in Fig. 13. In particular, Fig. 13(a) shows the comparison of ASR 70 peen type with media flowrate of $1 \mathrm{~kg} / \mathrm{min}$, while Fig. 13(b) shows comparison of ASR 230 peen type with media flowrate of $3 \mathrm{~kg} / \mathrm{min}$. It can be seen that the obtained process models can accurately represent peening processes for both ASR 70 and ASR 230 peen types. These obtained models are then used to develop the feedback MPC control system.

\subsubsection{Proxy model development}
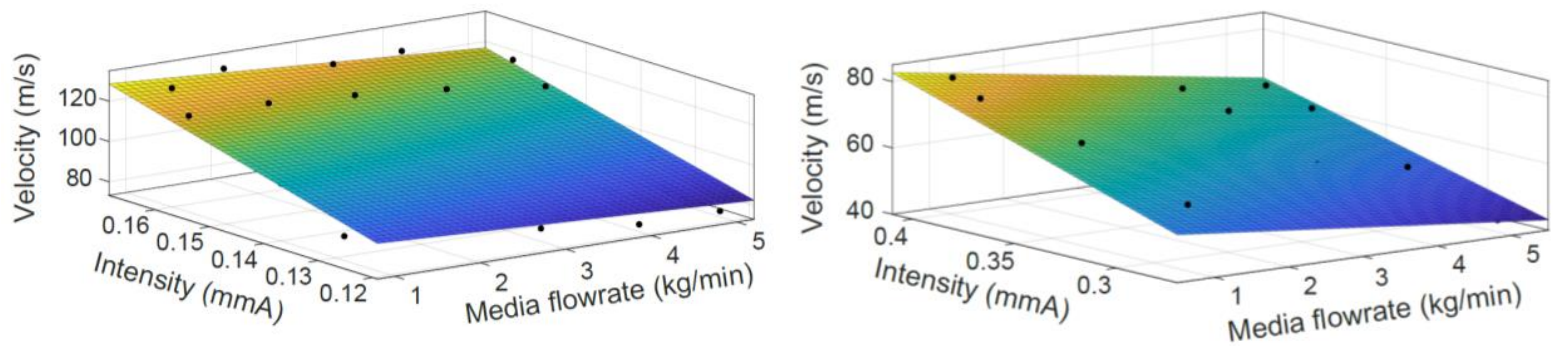

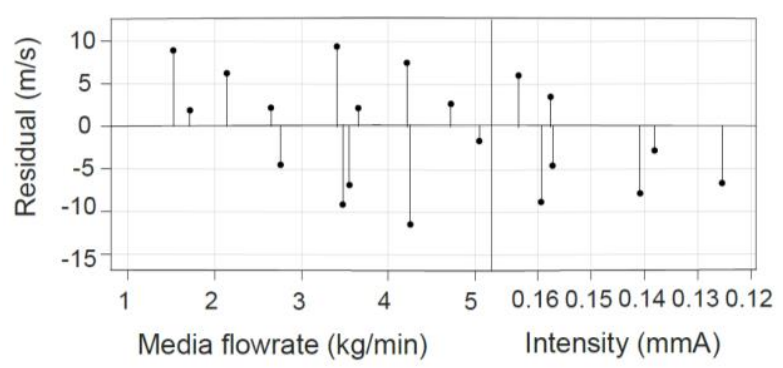

a)

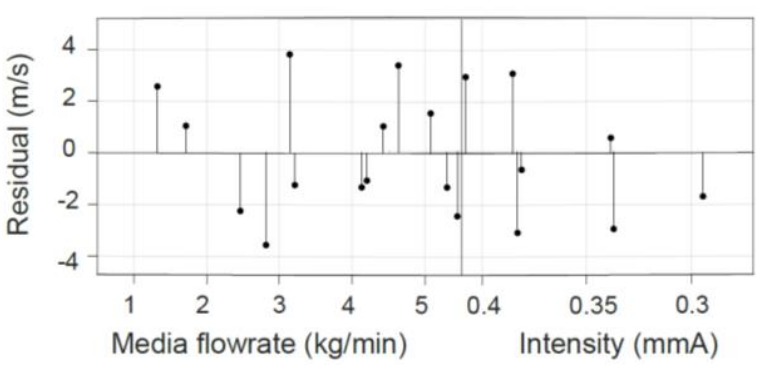

b)

Fig. 14: Comparison of the proxy model and the measurement data for shot stream velocity; (a) ASR 70 peen type and (b) ASR 230 peen type.

In this subsection, a proxy model is developed to translate the desired peening intensity to a value of shot stream velocity for the set-point setting in process monitoring. Using the same approach in Section 3, we can derive the proxy model using regression algorithm as below

$f_{\text {vel }}(x, y)=P_{0} * y+P_{1} * x * \ln \left(1.0-\frac{y}{P_{2} * S}\right)$.

In this model, $f_{v e l}(x, y)$ is shot stream velocity, $x$ is media flowrate, and $\mathrm{y}$ is intensity. Model parameters of $P_{0}, P_{1}$, and $P_{2}$ are evaluated using regression method. $S$ is also the peen type coefficient, in which, $S=70$ for ASR 70 peen type, while $S=230$ for ASR 230 peen type. For ASR 70 peen type, the obtained model parameters are $P_{0}=776.3, P_{1}=33.17$, and $P_{2}=0.031$, respectively. The root mean squared fit is 0.8451 and maximum residual is about $10.0(\mathrm{~m} / \mathrm{s})($ about $7.5 \%)$. For ASR 230 
peen type, the model parameters are $P_{0}=205.8$ and $P_{1}=58.76$ and $P_{2}=0.031$, respectively. The root mean squared fit is 0.9256 , while maximum residual is about $4.0(\mathrm{~m} / \mathrm{s})$ (about $4.5 \%$ ). Fig. 14 (a) shows plot of RSM of shot stream velocity and its experimental residual versus peening intensity and media flowrate for ASR 70 peen type, while Fig. 14(b) shows plot of RSM of shot stream velocity for ASR 230 peen type. It can be seen that shot stream velocity has a stronger correlation and is more sensitive to intensity, while it has a weaker correlation to media flowrate.

\subsubsection{Model predictive control development}

As mentioned, a single input and single output (SISO) MPC controller is designed to automatically obtain any target setting value of peening intensity through tracking shot stream velocity reference setpoints. In which, the shot stream velocity reference set-point is evaluated using proxy model for the target intensity and media flowrate. The only control input variable is inlet air pressure, while the only output variable is shot stream velocity. Thus, the objective function for the model predictive controller design is often expressed in the following form:

$\min _{u(t)} J(x(t), u(t))=\sum_{k=0}^{N p}\left(y^{\text {measure }}-y_{s p}\right)^{T} Q\left(y^{\text {measure }}-y_{s p}\right)+\sum_{k=0}^{N p} \Delta u^{T} R \Delta u$

Subject to

$\dot{x}=\boldsymbol{F}(x(t))+\boldsymbol{B} u(t)$,

$y=\boldsymbol{C} x(t)+\boldsymbol{D} \xi(t)$

$x(0)=x_{0}$,

$u_{\min } \leq u(t) \leq u_{\max }$

$\Delta u_{\min } \leq \Delta u(t) \leq \Delta u_{\max }$

In these control formulations, eqn. (7.1) is objective function of the process control with reference setpoints. $y_{s p}$ is shot stream velocity reference set-point obtained from target intensity. $y^{\text {measure }}$ is measurement value of the shot stream velocity. $\Delta u=u_{k}-u_{k-1}$ is a step change in regulated inlet air pressure. $Q$ is the state gain matrix. $R$ is the control gain matrix, while $N p$ is the number of prediction horizon. Both $Q$ and $R$ are defined and tuned during control design. Equation (7.2) is dynamical process model, which is obtained in subsection (4.3.1). In which, $\boldsymbol{F}$ can be a linear or nonlinear function, $\boldsymbol{B}$ is control operator, $x$ are the process model variables (or state variables), and $u$ is manipulated variable (in this study, it is inlet air pressure). Equation (7.3) is observation model, where $\boldsymbol{C}$ is observation operator, $\boldsymbol{D}$ is noise coefficient, $\xi$ is noise variable, $y$ is observation variable (or measurement variable, shot stream velocity). $x_{0}$ is initial condition of each step of process control. $u_{\text {min }}$ and $u_{\text {max }}$ are the minimum and maximum inlet pressure that the air compressor can supply to the peening system, respectively. $\Delta u_{\min }$ and $\Delta u_{\max }$ are the minimum and maximum step of air pressure that the regulator can adjust at each step, respectively. In process control, the controller determines a difference between the set-point and the actual measurement variable to optimally solve for a controller action $(\Delta u)$, which satisfy the constraints (7.5 and 7.6), using process model (7.2). The 
obtained control action $\Delta u$ is then sent to regulator (or inlet valve) to adjust the system for attaining the set-point. Fig. 15 shows control system design, while control action evaluation is performed using Algorithm 2 as bellow:

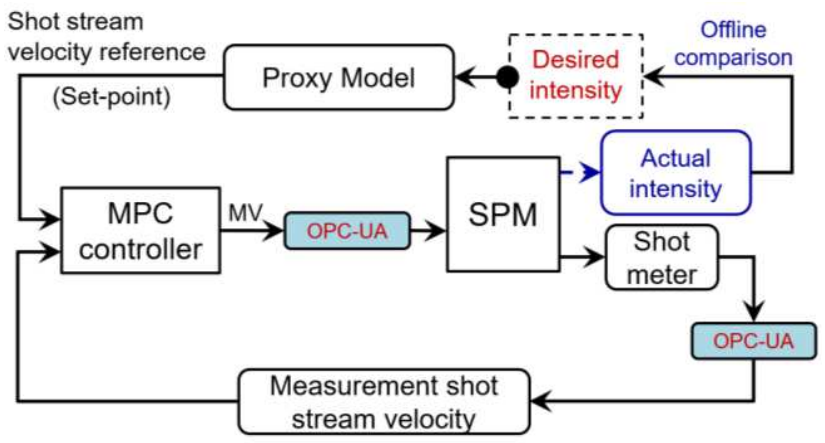

Fig. 15: Schematic diagram of the optimal feedback model predictive control system for shot peening machine using ShotMeter for shot stream velocity measurement.

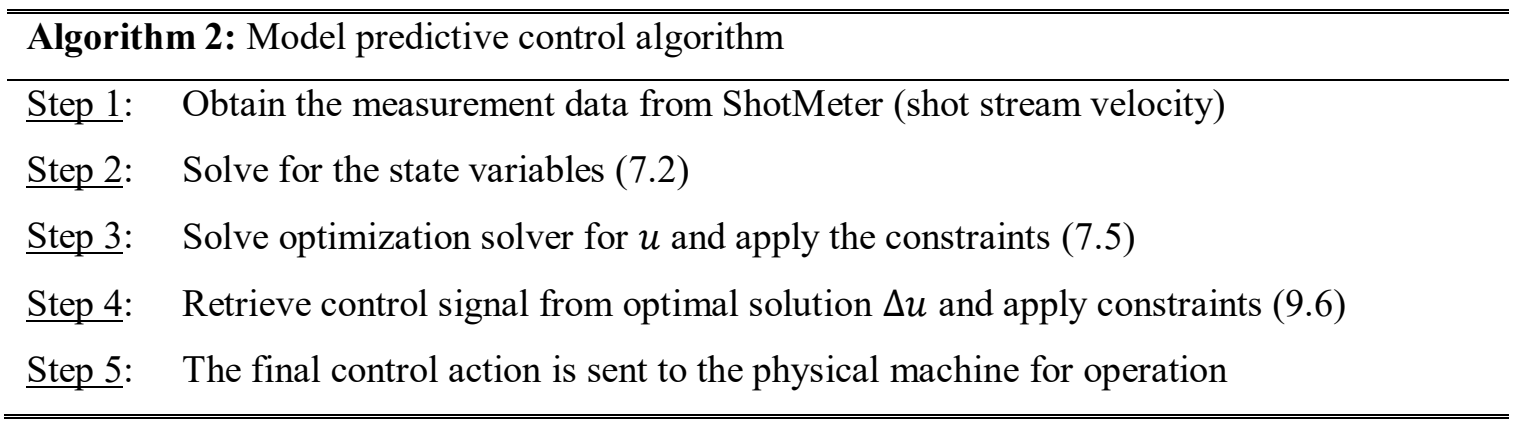

The control windows are determined by the constraints of the physical system. In which, $u_{\min }=1.0$ bars (or $14.5038 \mathrm{psi}$ ), $u_{\max }=4.5$ bars (or $\sim 65.0 \mathrm{psi}$ ), $\Delta u_{\min }=-0.02$ bars, and $\Delta u_{\max }=0.02$ bars. Number of prediction horizon, $N_{p}$, is set at 5 , while control horizon, $N_{c}$, is set at 4 . The process gain $Q=2$ and control gain $R=50$, which are chosen depending on the characteristics of the dynamical process to ensure that the control performance is stable and accurate. The time constant (delay time, $\tau$ ) is about 0.01 seconds. The control time step $(\Delta t)$ is 0.01 seconds. For the default case, the reference set-point is set at $50.0 \mathrm{~m} / \mathrm{s}$, while mass flowrate is set at $1 \mathrm{~kg} / \mathrm{min}$. In order to perform a peening process, we need to key in the target peening intensity, peen media flowrate, peen type, speed of robot arm, and exposure time from keyboard. The proxy model will automatically translate target setting intensity into a new reference set-point, while the controller will automatically adjust the inlet air pressure to attain the set-point and finally attain the target intensity.

\subsubsection{Control soft-launch demonstration}

In this study, control soft-launches are performed to demonstrate for control application of the proposed control development. In particular, two in-silico control scenarios are used in the demonstrations for both ASR 70 and ASR 230 peen types to attain different values of target intensity, 
respectively. Control scenarios of ASR 70 peen type for different intensities and other settings are listed in Table 2, while ASR 230 is shown in Table 3, as bellows:

Table 2: Control scenarios of different intensity with ASR 70 peen type

\begin{tabular}{|l|l|l|l|l|l|l|}
\hline $\begin{array}{l}\text { Target intensity } \\
(\mathrm{mmA})\end{array}$ & 0.1215 & 0.1320 & 0.1550 & 0.1655 & 0.1305 & 0.1200 \\
\hline $\begin{array}{l}\text { Processing time } \\
(\mathrm{s})\end{array}$ & $0-20$ & $20-100$ & $100-140$ & $140-180$ & $180-240$ & $240-300$ \\
\hline $\begin{array}{l}\text { Media flowrate } \\
(\mathrm{kg} / \mathrm{min})\end{array}$ & $1.0,2.0,3.0,4.0,5.0$ & & \\
\hline $\begin{array}{l}\text { Impinging angle } \\
\text { (deg) }\end{array}$ & 75 & $\begin{array}{l}\mid l \\
\text { Standoff } \\
\text { distance (mm) }\end{array}$ & 120 & & \\
\hline
\end{tabular}

Results of soft-launch control with designed SISO MPC are shown in Fig. 16(a) and (b) for typical media flowrate of 3.0 and $5.0(\mathrm{~kg} / \mathrm{min})$, respectively. Solid 'red-line' is shot stream velocity set point for target intensity, while solid 'black-line' is measurement output of shot stream velocity. The blue line is manipulated value of the inlet air pressure in (bar) to achieve the reference set-points. The results show that the process control is robust, stable, and accurate. The simulation time of the developed dynamical process model is suitable for real-time control requirements. It means that the shot velocity model is promising for real-time control system development of automated shot peening machine.
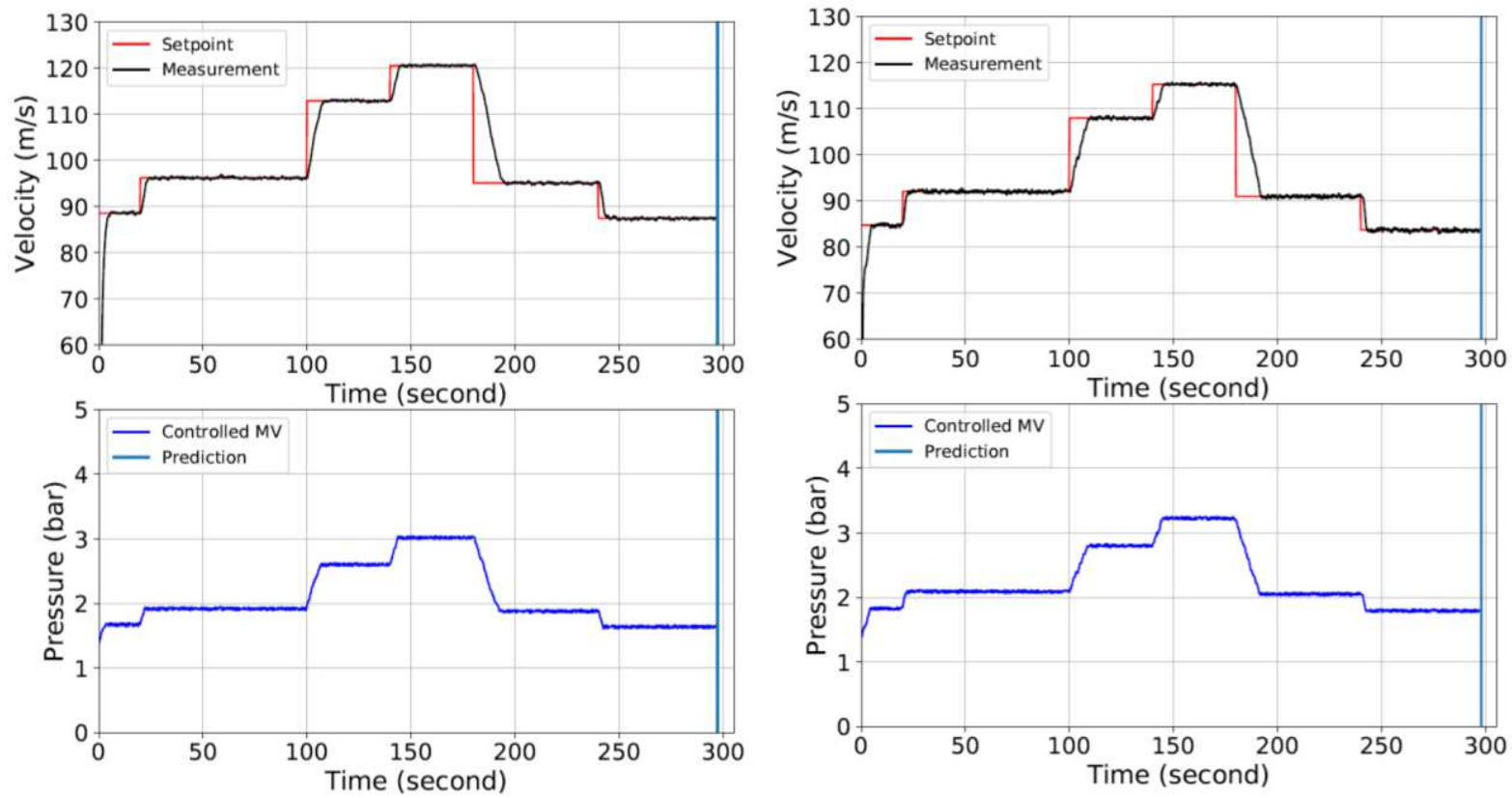

(a)

(b) 
Fig. 16: Results of control soft-launch with different values of intensity of the shot peening machine with ASR 70 peen type for different media flowrates: (a) media flowrate of $3 \mathrm{~kg} / \mathrm{min}$ and (b) media flowrate of $5 \mathrm{~kg} / \mathrm{min}$.

Table 3: Control scenarios of different intensity with ASR 230 peen type

\begin{tabular}{|l|l|l|l|l|l|l|}
\hline $\begin{array}{l}\text { Target intensity } \\
(\mathrm{mmA})\end{array}$ & 0.2450 & 0.3200 & 0.3450 & 0.3800 & 0.3400 & 0.2350 \\
\hline $\begin{array}{l}\text { Processing time } \\
(\mathrm{s})\end{array}$ & $0-20$ & $20-100$ & $100-140$ & $140-180$ & $180-240$ & $240-300$ \\
\hline $\begin{array}{l}\text { Media flowrate } \\
(\mathrm{kg} / \mathrm{min})\end{array}$ & $1.0,2.0,3.0,4.0,5.0$ & & \\
\hline $\begin{array}{l}\text { Impinging angle } \\
(\text { deg })\end{array}$ & 75 & $\begin{array}{l}\mid l \\
\text { Standoff } \\
\text { distance (mm) }\end{array}$ & 120 & & \\
\hline
\end{tabular}

Control results of the case for ASR 230 peen type are shown in Fig. 17 for media flowrate of 3.0 ( $\mathrm{kg} / \mathrm{min})$. Similarly, in Fig. 17, the solid 'red-line' is shot stream velocity set point for target intensity, while solid 'black-line' is measurement output of shot stream velocity. The blue line is manipulated value of the inlet air pressure in (bar) to achieve the reference set-points. The results show that the process control is robust, stable, and accurate. The simulation time of the developed dynamical process model is suitable for real-time control requirements.
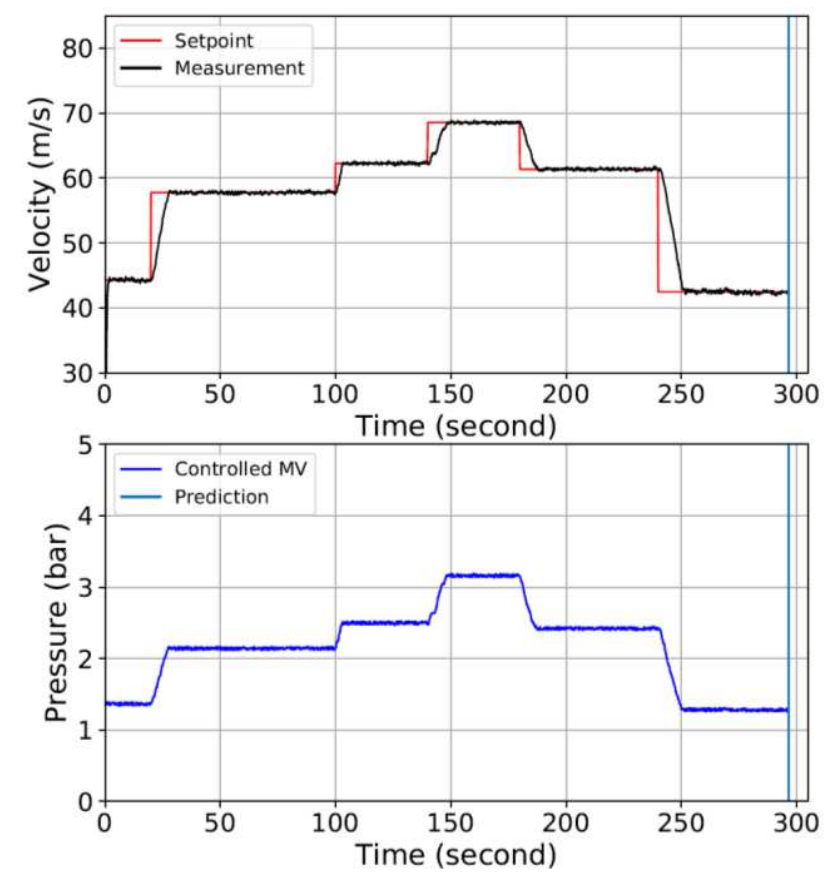
Fig. 17: Results of control soft-launch with different values of intensity of the shot peening machine with ASR 230 peen type for different media flowrate of $3 \mathrm{~kg} / \mathrm{min}$.

\section{Concluding remarks and recommendations}

A blended practical model of shot stream velocity upon impact is developed based on both the experimental data and candidate functions to accurately describe the response of shot stream velocity to any change of inlet air pressure and media flowrate. The nature of particle-air flow inside the peening system is used to select a suitable candidate functions for functional library, while the regression technique is employed to determine the sparse coefficients of the candidate function for the final shot stream velocity model expression.

The developed model is employed to predict the shot stream velocity of different peen types for different operating conditions. The developed model is also used to predict peening intensity for different peen types and operating conditions. The obtained results are in good agreement with the experimental data for the same operating conditions. These achievements may provide great information for operational setup in the actual production. In another word, it can greatly reduce the cost, time, labor, and material wastage to perform experimental trials to build saturation curve for practical guidance.

In addition, the developed shot stream velocity model is also applied to develop the dynamical process model for model-based process control system. An optimal feedback model predictive control system has been developed for fully automated shot peening machine based on simulated shot stream velocity to attain targeted intensity. In-silico control scenarios are performed for two different peen types to automatically achieve desired intensities. The obtained results show that the process control performance is fast, stable, accurate, and reliable. It implies that the developed model-based control is suitable and can be utilized for actual peening operations.

\section{Acknowledgements}

This study is supported by the A*STAR Science and Engineering Research Council (SERC), under its RIE2020 Advanced Manufacturing and Engineering IAF-PP Programme (Grant No: A1894a0032).

\section{Declarations}

We confirm that this paper is original and has not been published elsewhere nor is it currently under consideration for publication elsewhere.

\section{- Funding}

This work is supported by the project entitled: "Machine Learning Assisted Control of Shot Peening Process" under Grant number A1894a0032 at Institute of High Performance Computing (IHPC) and Advanced Remanufacturing and Technology Centre (ARTC), A*STAR Singapore. 
- Conflicts of interest/Competing interests (include appropriate disclosures)

The authors declare that they have no known competing financial interests or personal relationships that could have appeared to influence the work reported in this paper.

- Availability of data and material (data transparency)

The authors will make availability of any related data to this manuscript if requested (or data will available on request).

\section{- Authors' contributions}

1) Van Bo Nguyen: Developed blended empirical model of shot stream velocity, designed and performed the predictions and control system, developed and performed in-silico control scenarios, developed ideas for this paper, analyzed data, wrote original and revised paper.

2) Augustine Teo: Design experiments, performed experiments, analyzed data and revised paper.

3) Te Ba: Discussed, analyzed data and revised paper.

4) Kunal Ahluwalia: Provided some idea on experimental setup, analyzed data, and revised paper.

5) Ampara Aramcharoen: Provide ideas on experimental trials and revised paper.

6) Chang Wei Kang: Managed and provided direction for research development, provided ideas on control design, analyzed data and revised paper.

\section{- Ethics approval}

Not applicable

- Consent to participate

Not applicable

- Consent for publication

Not applicable

\section{References}

[1] David Kirk (1999) Shot peening. International Journal of Aircraft Engineering and Aerospace Technology 77: 349-361. MCB University Press. ISSN 0002-2667.

[2] Burrell NK (1985) Controlled Shot Peening of Automotive Components. SAE Transactions 94: 4451. www.jstor.org/stable/44721548.

[3] Baiker S (2006) Shot Peening: A Dynamic Application and Its Future. Metal Finishing News. https://books.google.com.sg/books?id=zgVZnQAACAAJ

[4] Marsh KJ (1993) Shot Peening: Techniques and Applications. Engineering Materials Advisory Services Ltd., London.

[5] Almen JO, Black PH (1963) Residual Stresses and Fatigue in Metals. McGraw-Hill, Toronto.

[6] Anon (1989) Shot Peening of Metal Parts. Military Specification Mil-S-13165c.

[7] David Kirk (2016) Peening Intensity: True meaning and measurement Strategy. The Shot Peener 3: (3). https://www.shotpeener.com/library/pdf/2016030.pdf 
[8] David Kirk (2005) Theoretical principal of shot peening coverage. The Shot Peener 19 (2): 24-26. https://www.shotpeener.com/library/pdf/2005145.pdf

[9] Franck Petit-Renaud (2018) Optimization of the Shot Peening Parameters. The Shot Peener. https://www.shotpeener.com/library/pdf/2002018.pdf

[10] Miao HY, Larose S, Perron C, Lévesque M (2010) An analytical approach to relate shot peening parameters to Almen intensity. Surface \& Coatings Technology 205(7): 2055-2066. https://doi.org/10.1016/j.surfcoat.2010.08.105

[11] Jack Champaigne (1992) Shot Peening Intensity Measurement. The Shot Peener 6(4): 1-6. https://www.shotpeener.com/library/pdf/1992082.pdf

[12] David Kirk (2018) Almen Strip Quality. The Shot Peener 32(3): 26-36. https://www.shotpeener.com/library/detail.php?anc=2018034

[13] David Kirk (2015) Verification of Peening Intensity. The Shot Peener 29(4): 28-36. https://www.shotpeener.com/library/detail.php?anc=2015045

[14] Cammett J (2007) Shot peening coverage: the real deal. The Shot Peener 21(3): 8-14. https://www.shotpeener.com/library/pdf/2007018.pdf

[15] David Kirk (2014) Quantification of shot peening coverage. The Shot Peener 28(4): 22-34. https:/www.electronics-inc.com/wp-content/uploads/ QuantificationOfShotPeening Coverage.pdf

[16] SAE J2277 (2013) Shot Peening Coverage Determination. SAE International. https://infostore.saiglobal.com/en-us/Standards/SAE-J-2277-2013-1021238 SAIG

$\underline{\text { SAE SAE } 2378326 /}$

[17] Tu F, Delbergue D, Miao HY, Klotz T, Brochu M, Bocher P, Lévesque M (2017) A sequential DEM-FEM coupling method for shot peening simulation. Surface and Coatings Technology 319: 200-212, https://doi.org/10.1016/j.surfcoat.2017.03.035.

[18] Zhang Y, Lai F, Qu S, Ji V, Liu H, Li X (2020) Effect of shot peening on residual stress distribution and tribological behaviors of $17 \mathrm{Cr} 2 \mathrm{Ni} 2 \mathrm{MoVNb}$ steel. Surface and Coatings Technology 386. https://doi.org/10.1016/j.surfcoat.2020.125497.

[19] Gariépy A, Miao HY, Lévesque M (2017) Simulation of the shot peening process with variable shot diameters and impacting velocities. Advances in Engineering Software 14: 121-133. https://doi.org/10.1016/j.advengsoft.2017.06.011.

[20] Nguyen VB, Poh HJ, Zhang YW (2014) Predicting shot peening coverage using multiphase computational fluid dynamics simulations. Powder Technology 256: 100-112. https://doi.org/10.1016/j.powtec.2014.01.097

[21] Lin Q, Liu H, Zhu C, Chen C, Zhou S (2020) Effects of different shot peening parameters on residual stress, surface roughness and cell size. Surface and Coatings Technology 398. https://doi.org/10.1016/j.surfcoat.2020.126054

[22] Miao HY, Larose S, Perron C, Lévesque M (2010) An analytical approach to relate shot peening parameters to Almen intensity. Surface \& Coatings Technology 205(7): 2055-2066. https://doi.org/10.1016/j.surfcoat.2010.08.105 
[23] Seddik R, Bahloul A, Atig A, Fathallah R(2017) A simple methodology to optimize shot-peening process parameters using finite element simulations. Int J Adv Manuf Technol. 90: 2345-2361. https://doi.org/10.1007/s00170-016-9532-1

[24] Nam YS, Jeon U, Yoon HK, Shin BC, Byun JH (2016) Use of response surface methodology for shot peening process optimization of an aircraft structural part. Int. J. Adv. Manuf. Technol. 87: 2967-2981. https://doi.org/10.1007/s00170-016-8690-5

[25] Wang X, Wang Z, Wu G, Gan J, Yang Y, Huang H, He J, Zhong H (2019) Combining the finite element method and response surface methodology for optimization of shot peening parameters. Int. J. of Fatigue 129:. https://doi.org/10.1016/j.ijfatigue. 2019.105231

[26] Okan Unal (2016) Optimization of shot peening parameters by response surface methodology. Surface and Coatings Technology 305: 99-109. https://doi.org/10.1016/j.surfcoat. 2016.08.004

[27] David Kirk (2002) Curve Fitting for Shot Peening Data Analysis. The Shot Peener 16(1): 6https://www.shotpeener.com/library/pdf/2002139.pdf

[28] David Kirk (2007) Generation of Air-Blast Shot Velocity. The Shot Peener 20(1): 24-30. https://www.shotpeener.com/library/pdf/2016038.pdf.

[29] Teo A, Ahluwalia K, Aramcharoen A (2020) Experimental investigation of shot peening: correlation of pressure and shot velocity to Almen intensity. Int J Adv Manuf. Technol 106: 48594868. https://doi.org/10.1007/s00170-020-04982-y.

[30] Nguyen VB, Te B, Teo A, Ahluwalia K, Aramcharoen A, Kang CW (2020) Process Model for Evaluating the Peen Velocity in Shot Peening Machine. In: Itoh S., Shukla S. (eds) Advanced Surface Enhancement. INCASE 2019. Lecture Notes in Mechanical Engineering. Springer, Singapore. https://doi.org/10.1007/978-981-15-0054-1_4

[31] Bill Barker (2005) ShotMeter: A new tool for evaluating Shot Peening Intensity. The Shot Peener 2005: 16-30. https://www.shotpeener.com/library/pdf/2005016.pdf

[32] Hribernik A, Bombek G, Markočič I (2003) Velocity measurements in a shotblasting machine. Flow Measurement and Instrumentation 14(6): 225-231. https://doi.org/10.1016/ S09555986(03)00041-4

[33] Barker B, Young K, Pouliot L (2005) Particle velocity sensor for improving shot peening process control, Proceedings of ICSP9: 385-391.

[34] Kubler RF, Rotinat R, Badreddine J, Puydt Q (2020) Experimental Analysis of the Shot Peening Particle Stream Using Particle Tracking and Digital Image Correlation Techniques. Exp Mech 60: 429-443. https://doi.org/10.1007/s11340-019-00574-4

[35] Ohta T, Ma N (2020) Shot velocity measurement using particle image velocimetry and a numerical analysis of the residual stress in fine particle shot peening. Journal of Manufacturing Processes 58: 1138-1149. https://doi.org/10.1016/i.jmapro.2020.08.059

[36] Ohta T, Ma N (2020) Measurement of shot velocity using particle image velocimetry and numerical analysis of residual stress at two shot peening conditions. Mechanical Engineering Journal 7(4): 00152- . https://doi.org/10.1299/mej.20-00152. 
[37] https://www.progressivesurface.com/shotpeening/shotmeter-g3-particle-velocity-sensor.htm

[38] https://www.progressivesurface.com/casestudies/shotmeter-particle-velocity-sensor.htm

[39] Motulsky HJ, Ransnas LA (1987) Fitting curves to data using nonlinear regression: a practical and nonmathematical review. The FASEB Journal 1: 365-374. https://doi.org/10.1096/fasebj. $\underline{1.5 .3315805}$

[40] Duggleby RG (1981) A nonlinear regression program for small computers. Analytical Biochemistry 110 (1): 9-18. https://doi.org/10.1016/0003-2697(81)90104-4.

[41] Brunton SL, Proctor JL, Kutz JN (2016) Sparse Identification of Nonlinear Dynamics with Control (SINDYc). IFAC-Papers Online 49(18): 710-715. https://doi.org/10.1016/j.ifacol.2016.10.249

[42] Kaiser E, Kutz JN, Brunton SL (2018) Sparse identification of nonlinear dynamics for model predictive control in the low-data limit. Proceedings of the Royal Society A: Mathematical, Physical and Engineering Sciences 474 (2219): 20180335, https://royalsociety publishing.org/doi/abs/10.1098/rspa.2018.0335 


\section{List of figure captions}

Fig. 1: Abrasive Engineering shot peening machine (left) and Schematic diagram of experimental setup with mounted sensor location and ShotMeter (right).

Fig. 2: Experimental setup for peening intensity measurement

Fig. 3: Measurement shot stream velocity for different operating conditions.

Fig. 4: Averaged shot stream velocity for different media flowrate and inlet air pressure.

Fig. 5: Measurement peening intensity: (a) Almen gage for measuring the arc height to plot the saturation curve and measurement intensity, (b) peened Almen strips with before and after arc height information, and (c) Plotted saturation curve with determined intensity $(\mathrm{I}=0.136 \mathrm{mmA})$ and exposure time $(\mathrm{T} 1=1.21 \mathrm{~s})$.

Fig. 6: Averaged measurement values of peening intensity for different operating conditions of inlet air pressure and media flowrate.

Fig. 7: Averaged shot stream velocity vs. inlet pressure for ASR 70 peen type using exponential curve fitting of $\left(f_{1}=P_{0}\left(1-\exp \left(-P_{1} * p_{\text {inlet }}\right)\right)\right)$.

Fig. 8: Averaged shot stream velocity plots against the pressure drop for peen type of ASR 70 using exponential fitting function.

Fig. 9: Averaged shot stream velocity plots against peen mass flowrate for ASR 70 peen type using fitting function.

Fig. 10: Comparison of blended model with experimental data (upper) and the residual fits (lower).

Fig. 11: Comparison of predicted shot stream velocity and the experimental data of ASR 230 peen type for different operational input conditions.

Fig. 12: Comparison of predicted intensity and experimental data for different operational input conditions: (a) ASR 70 peen type and (b) ASR 230 peen type.

Fig. 13: Comparison of shot stream velocity using SINDy process model and experimental data for the same input pressure: (a) ASR 70 peen type and (b) ASR 230 peen type.

Fig. 14: Comparison of the proxy model and the measurement data for shot stream velocity; (a) ASR 70 peen type and (b) ASR 230 peen type.

Fig. 15: Schematic diagram of the optimal feedback model predictive control system for shot peening machine using ShotMeter for shot stream velocity measurement.

Fig. 16: Results of control soft-launch with different values of intensity of the shot peening machine with ASR 70 peen type for different media flowrates: (a) media flowrate of $3 \mathrm{~kg} / \mathrm{min}$ and (b) media flowrate of $5 \mathrm{~kg} / \mathrm{min}$.

Fig. 17: Results of control soft-launch with different values of intensity of the shot peening machine with ASR 230 peen type for different media flowrate of $3 \mathrm{~kg} / \mathrm{min}$. 

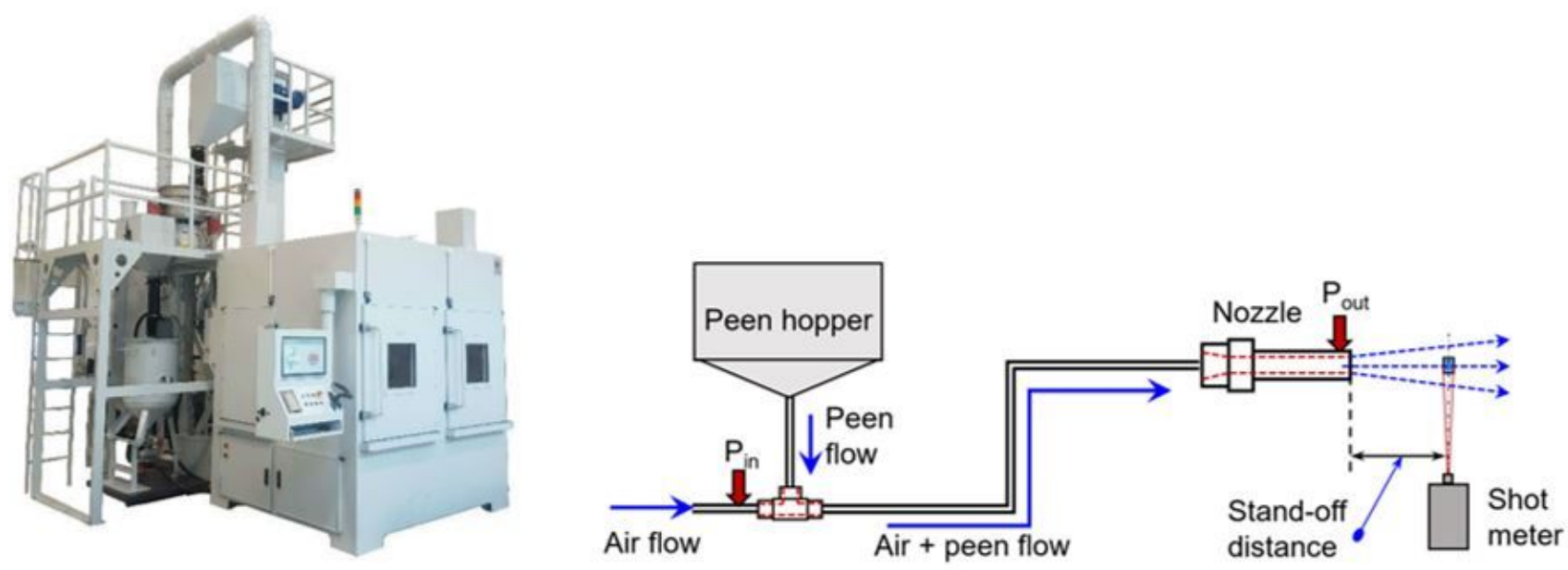

Figure 1

Abrasive Engineering shot peening machine (left) and Schematic diagram of experimental setup with mounted sensor location and ShotMeter (right).

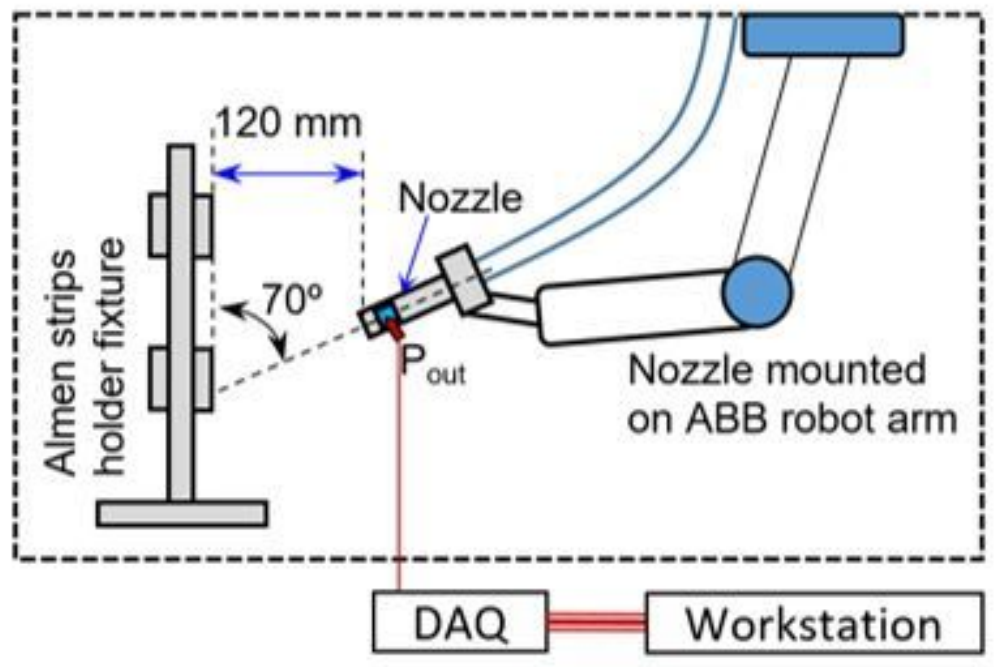

Figure 2

Experimental setup for peening intensity measurement 


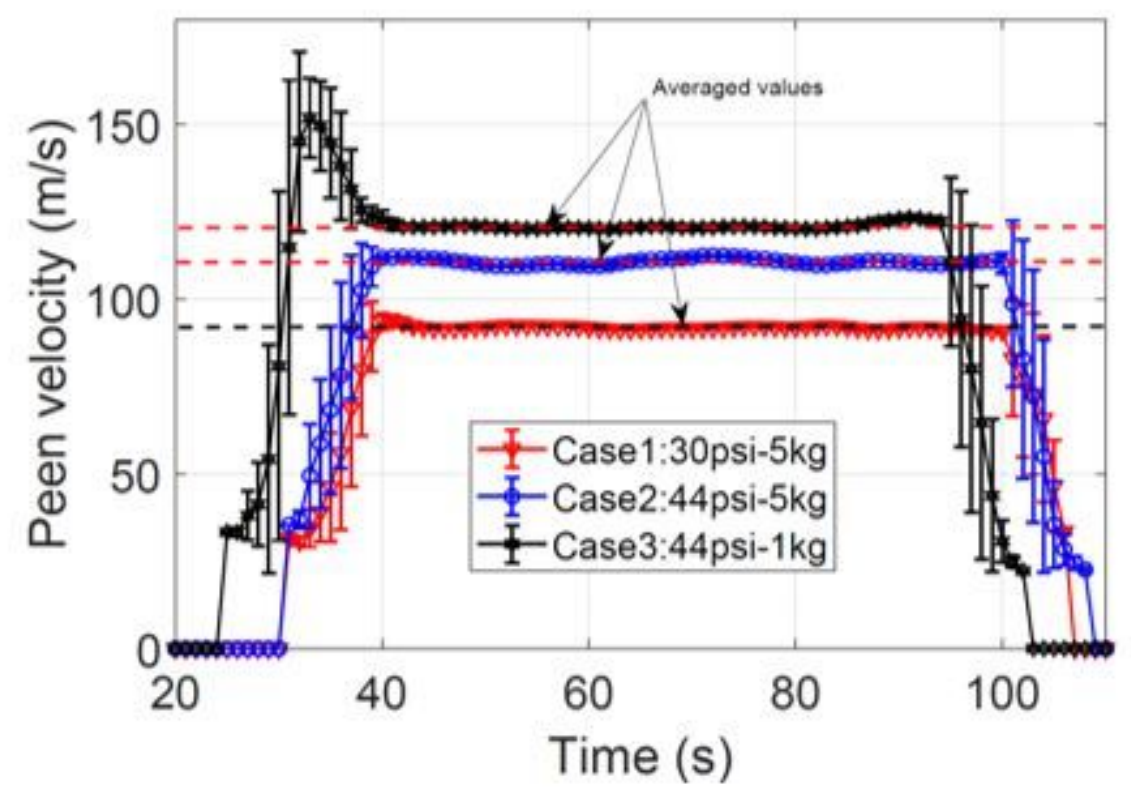

Figure 3

Measurement shot stream velocity for different operating conditions.

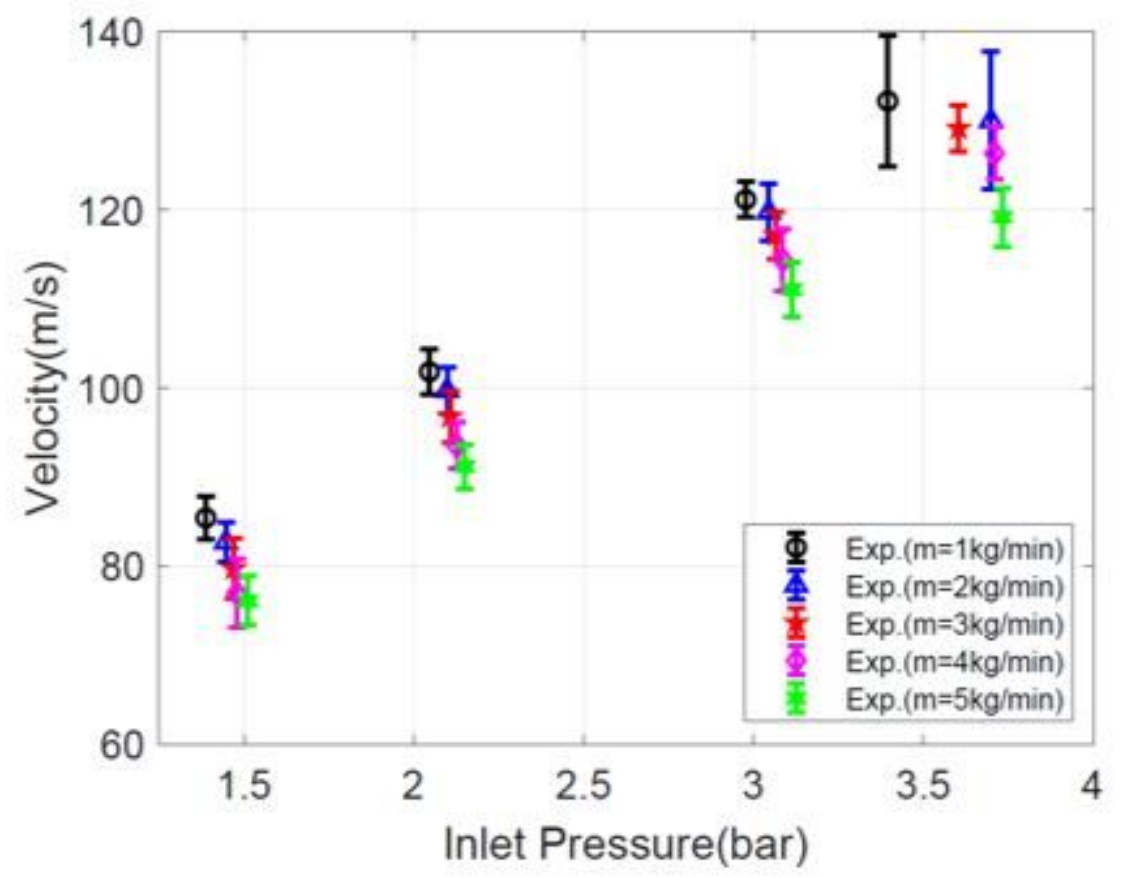

Figure 4

Averaged shot stream velocity for different media flowrate and inlet air pressure. 


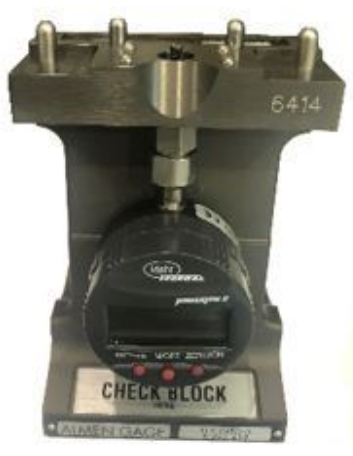

(a)

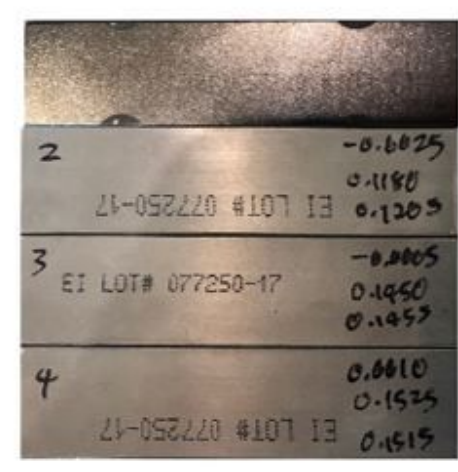

(b)

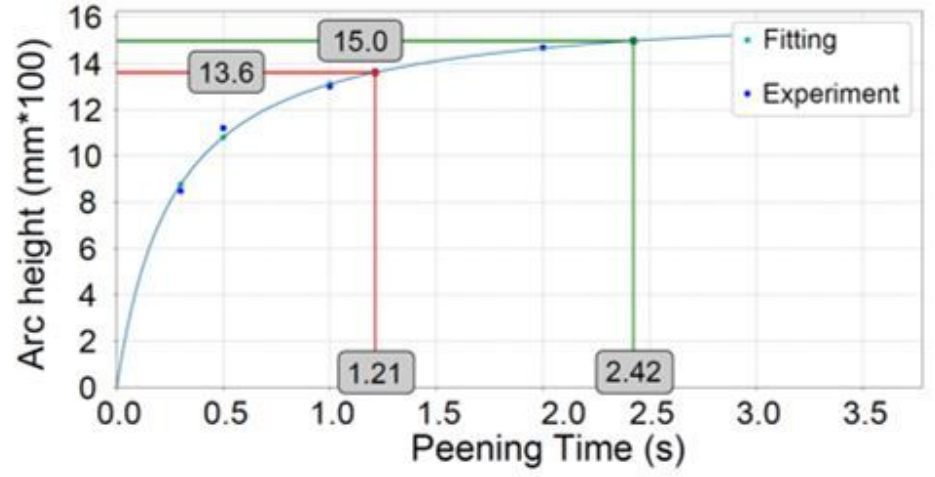

(c)

\section{Figure 5}

Measurement peening intensity: (a) Almen gage for measuring the arc height to plot the saturation curve and measurement intensity, (b) peened Almen strips with before and after arc height information, and (c) Plotted saturation curve with determined intensity $(\mathrm{I}=0.136 \mathrm{mmA})$ and exposure time $(T 1=1.21 \mathrm{~s})$.

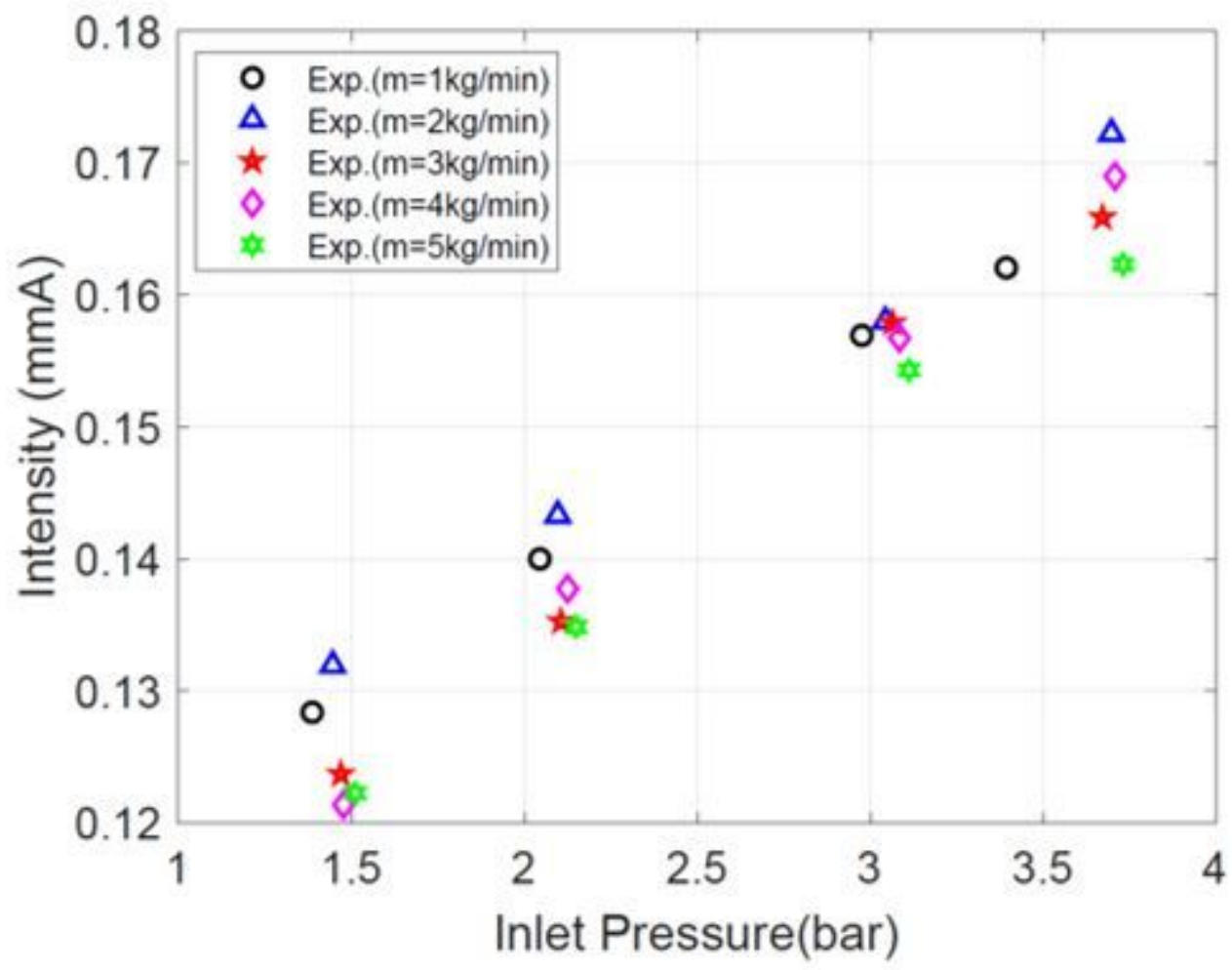

Figure 6

Averaged measurement values of peening intensity for different operating conditions of inlet air pressure and media flowrate. 


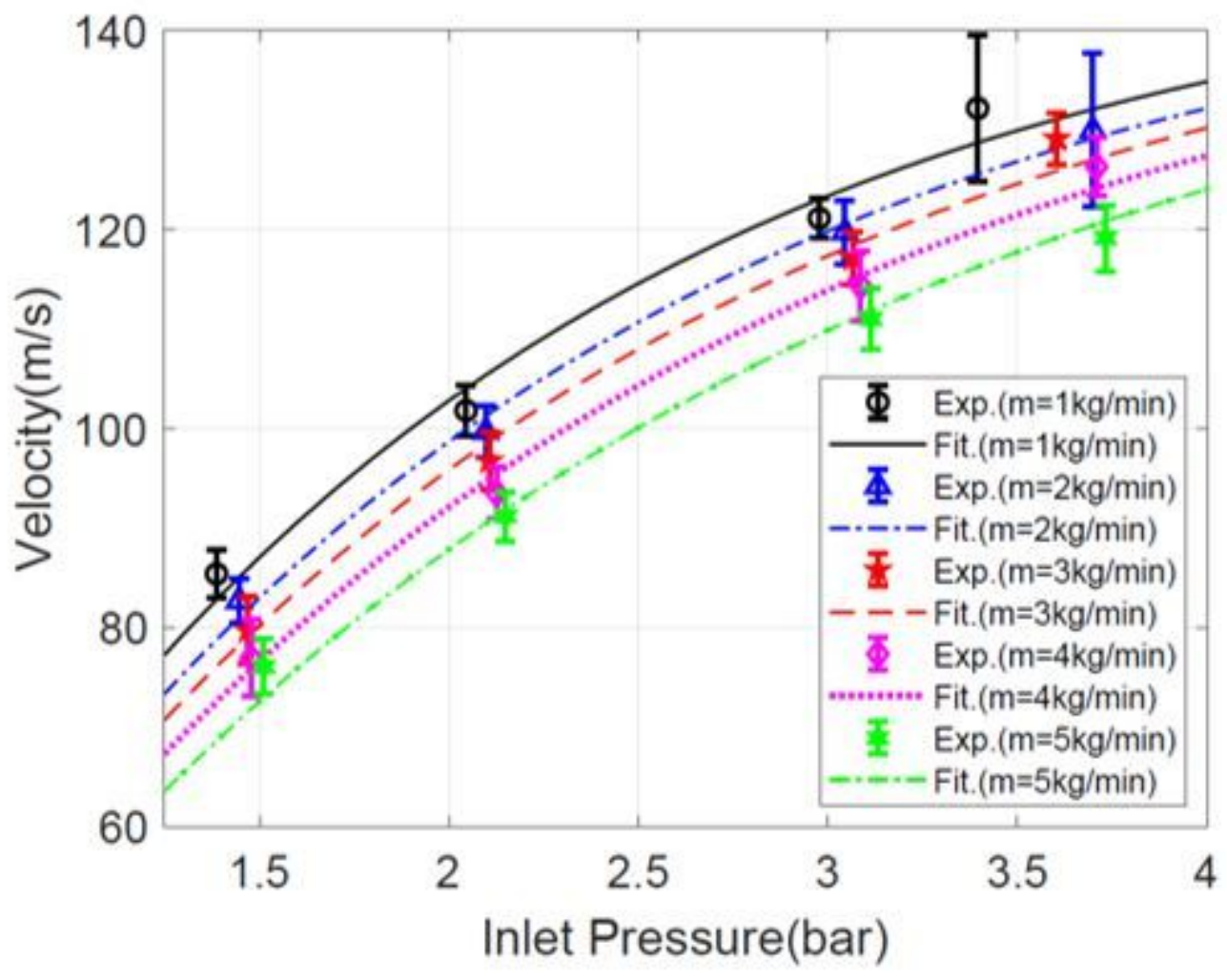

\section{Figure 7}

please see the manuscript file for the full caption

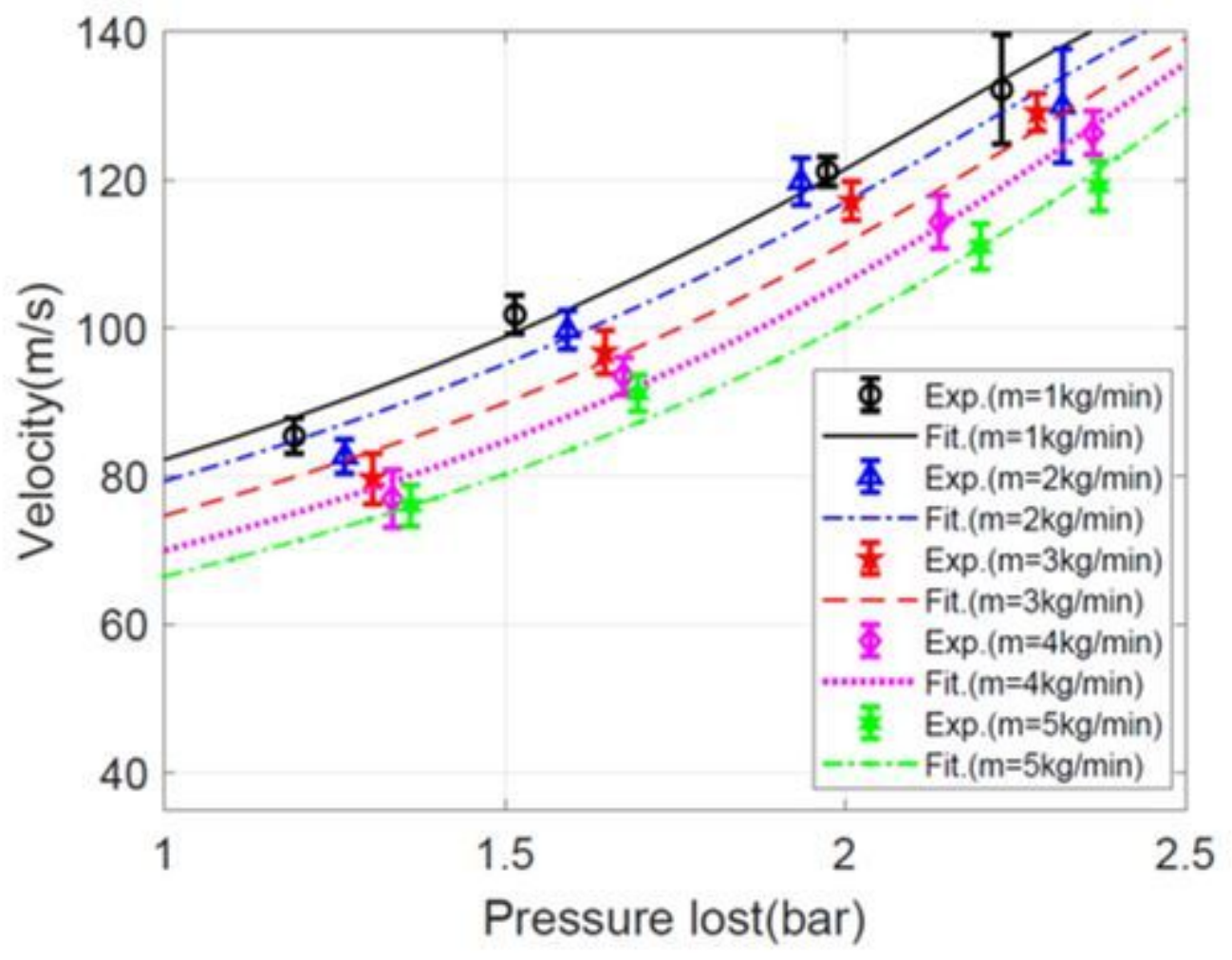




\section{Figure 8}

Averaged shot stream velocity plots against the pressure drop for peen type of ASR 70 using exponential fitting function.

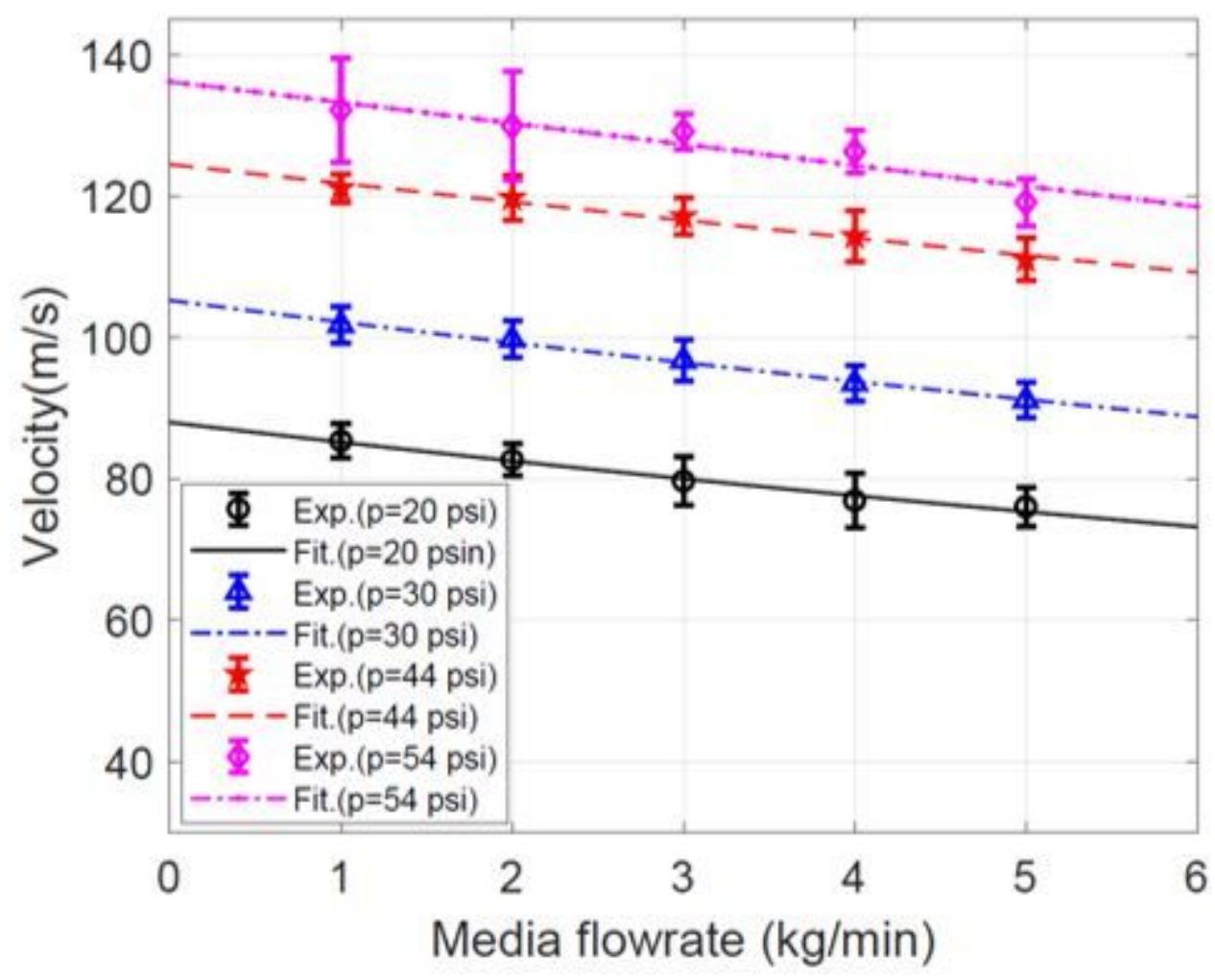

Figure 9

Averaged shot stream velocity plots against peen mass flowrate for ASR 70 peen type using fitting function. 

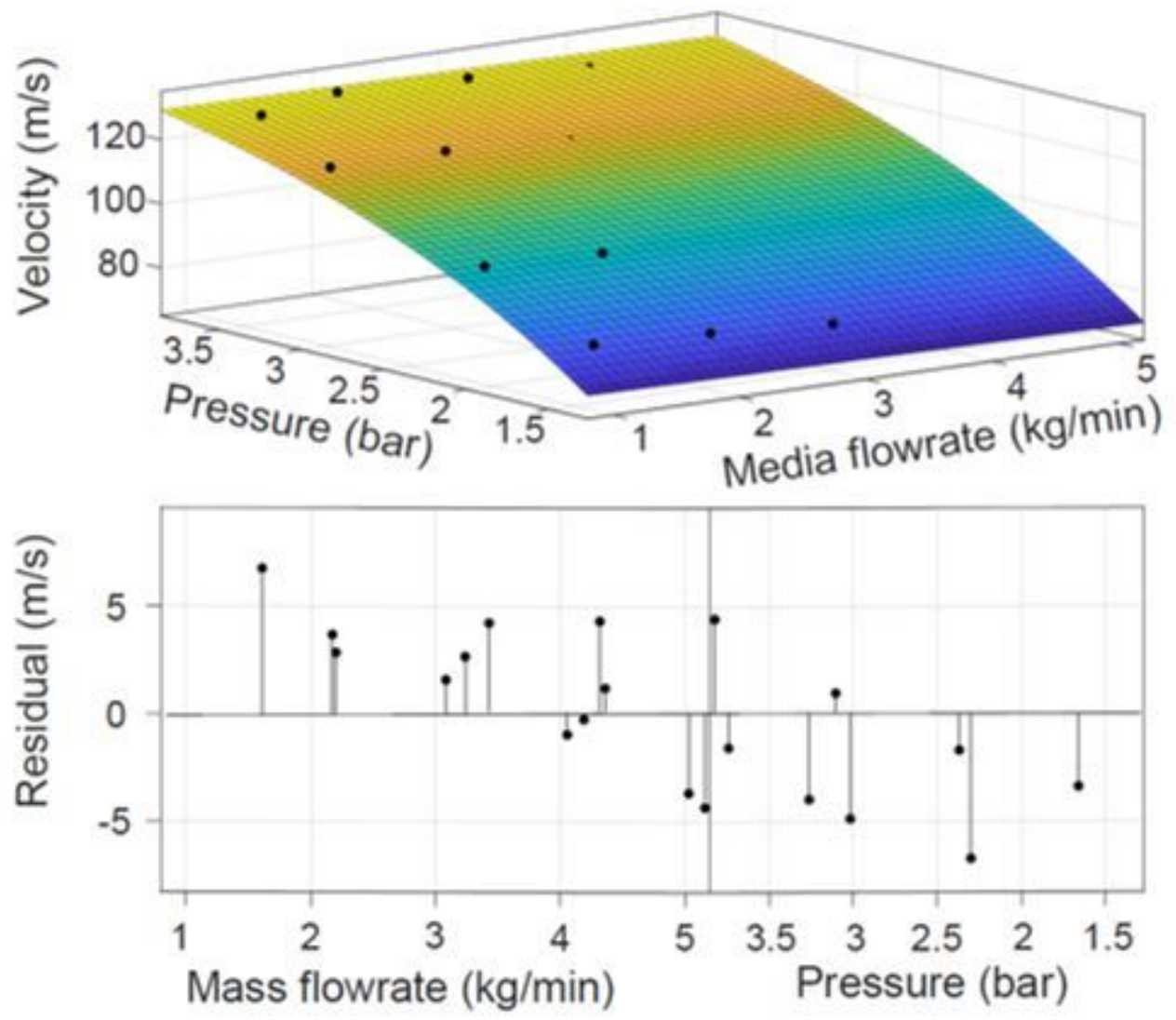

Figure 10

Comparison of blended model with experimental data (upper) and the residual fits (lower). 


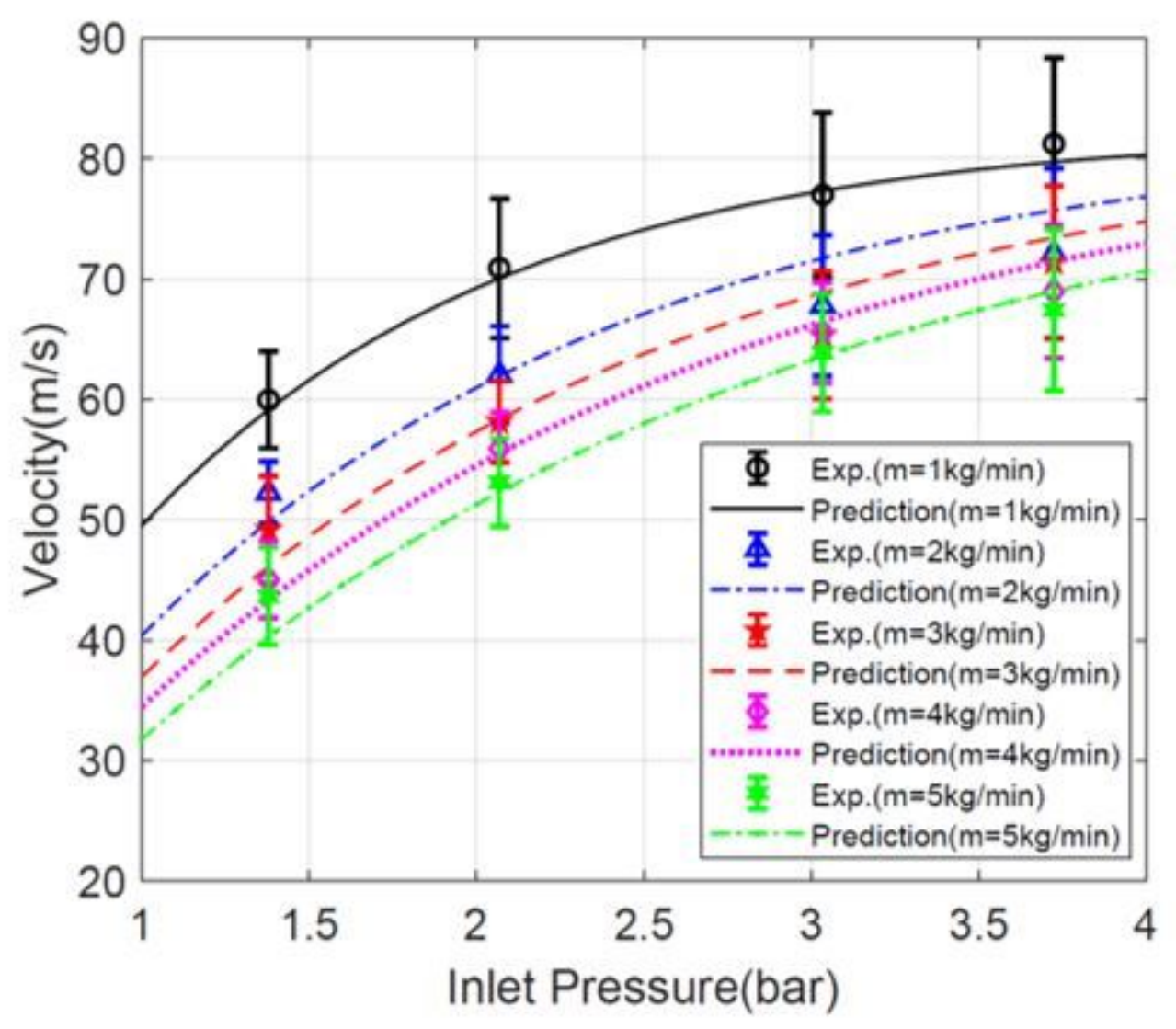

\section{Figure 11}

Comparison of predicted shot stream velocity and the experimental data of ASR 230 peen type for different operational input conditions.

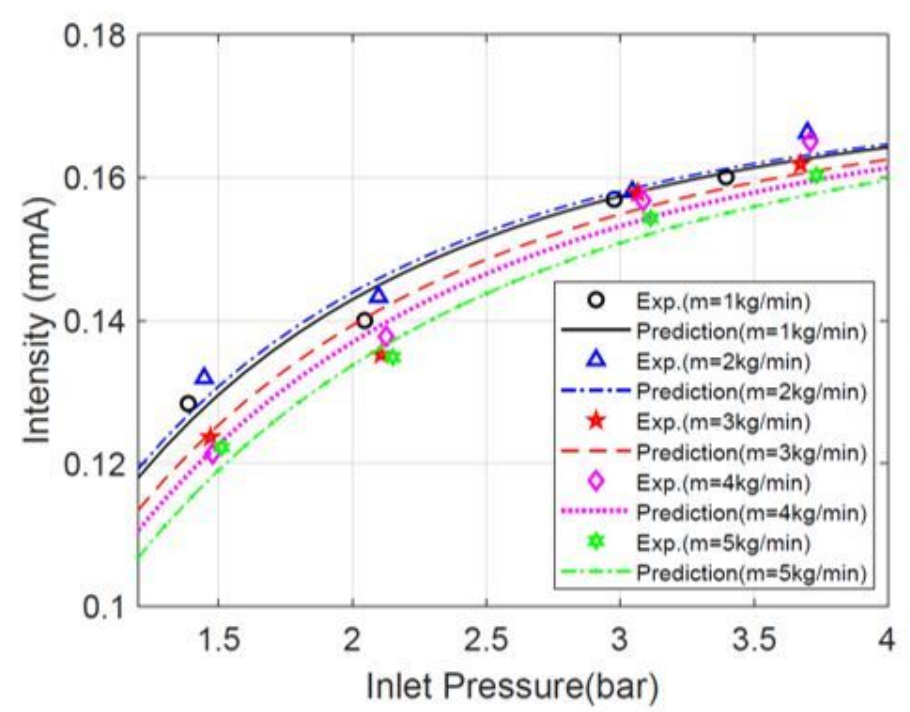

(a)

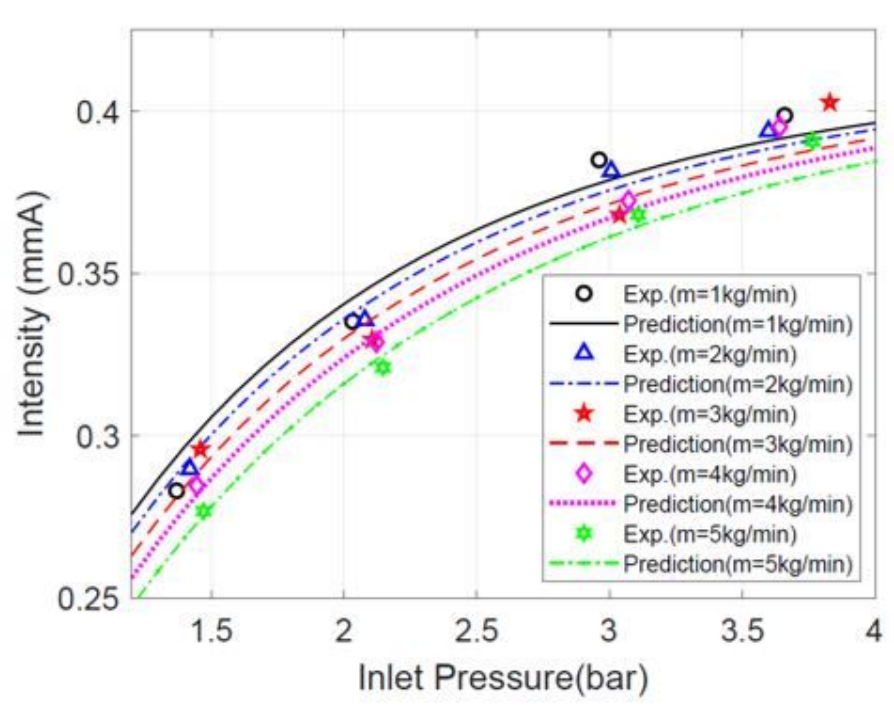

(b)

Figure 12 
Comparison of predicted intensity and experimental data for different operational input conditions: (a) ASR 70 peen type and (b) ASR 230 peen type.
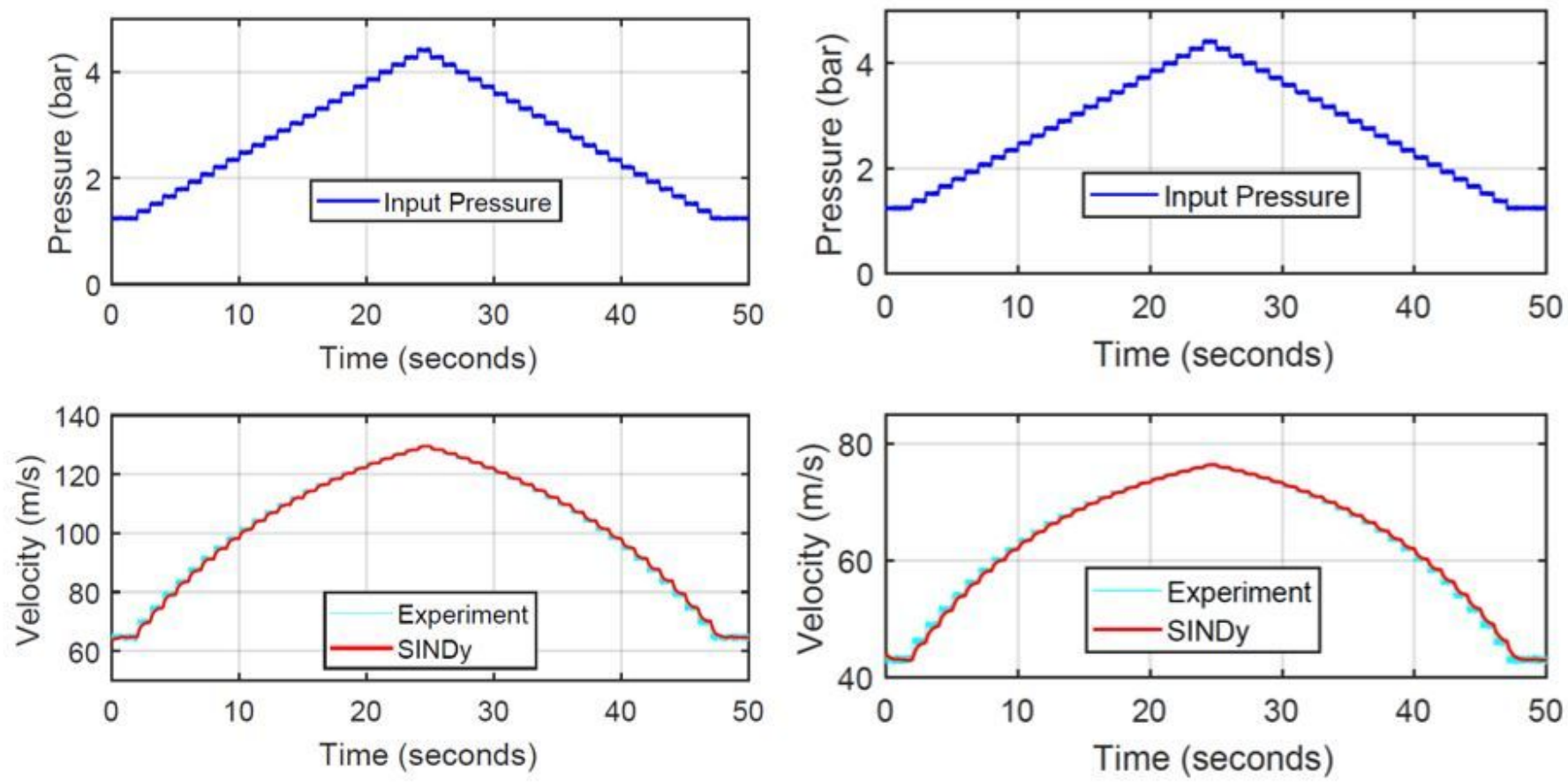

a)

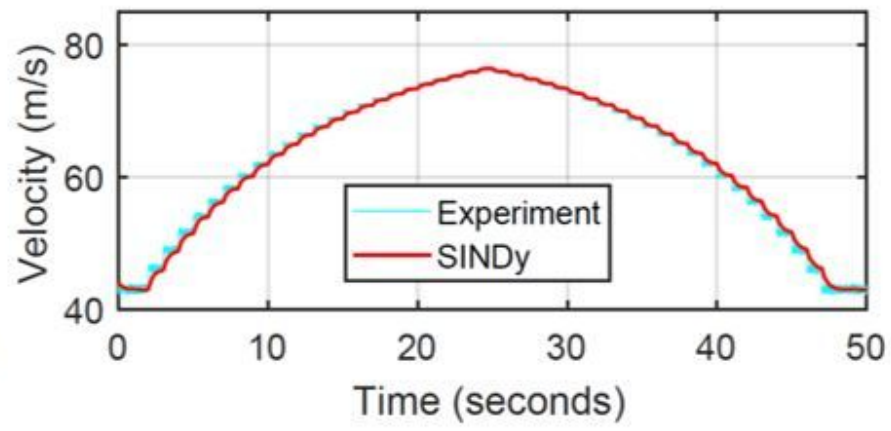

b)

\section{Figure 13}

Comparison of shot stream velocity using SINDy process model and experimental data for the same input pressure: (a) ASR 70 peen type and (b) ASR 230 peen type.
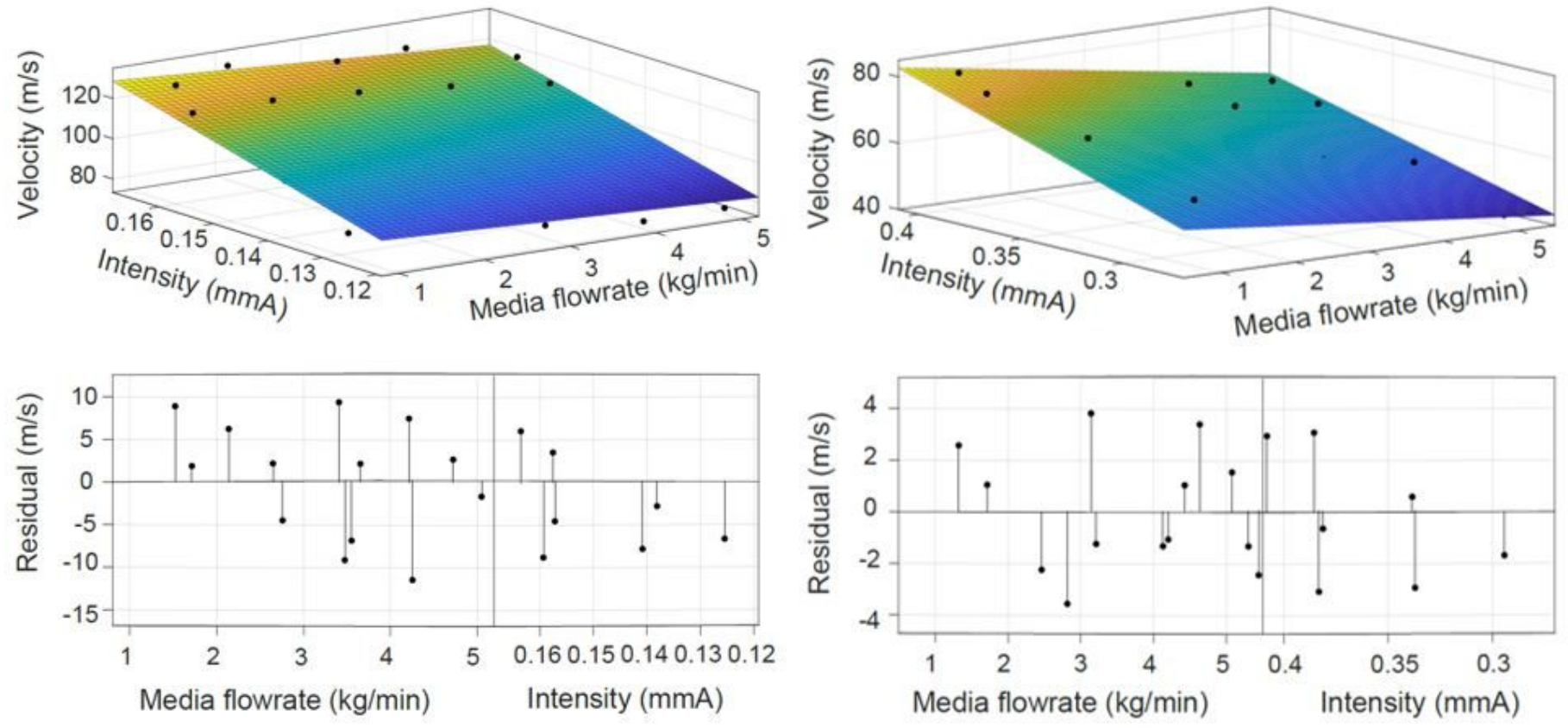

a)

b) 
Figure 14

Comparison of the proxy model and the measurement data for shot stream velocity; (a) ASR 70 peen type and (b) ASR 230 peen type.

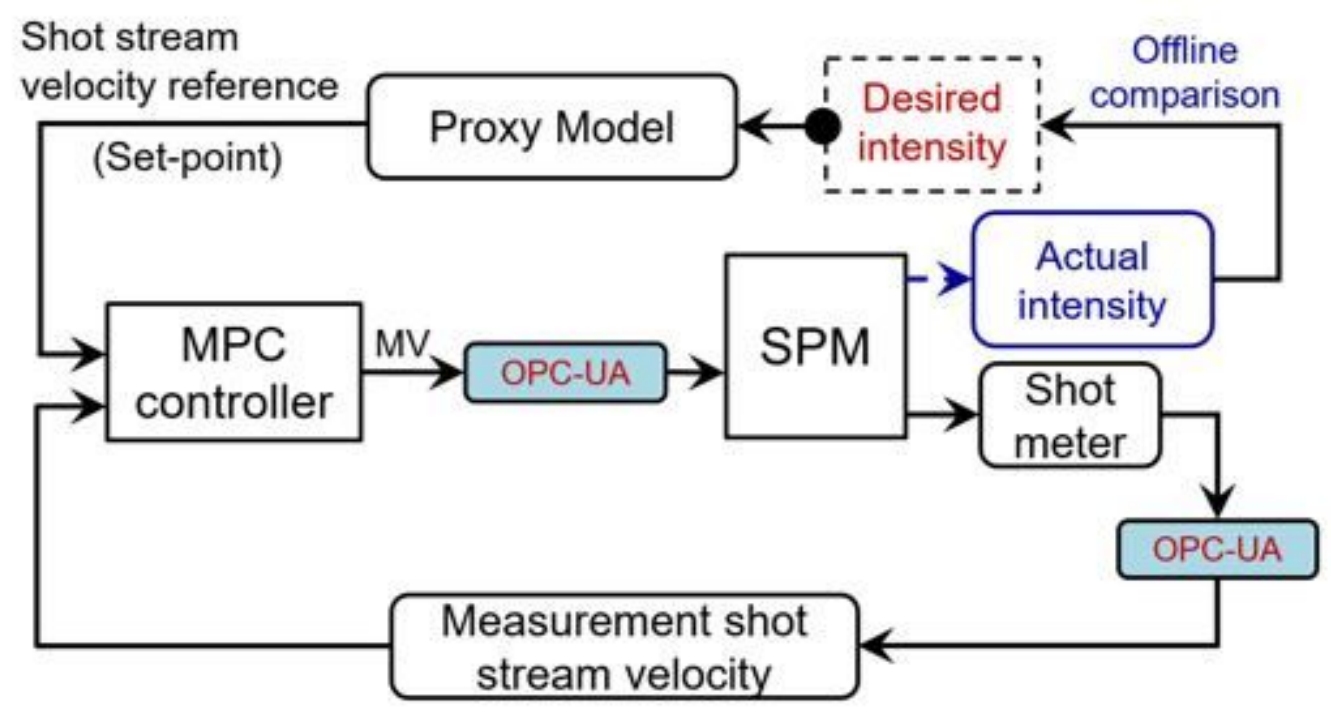

\section{Figure 15}

Schematic diagram of the optimal feedback model predictive control system for shot peening machine using ShotMeter for shot stream velocity measurement.
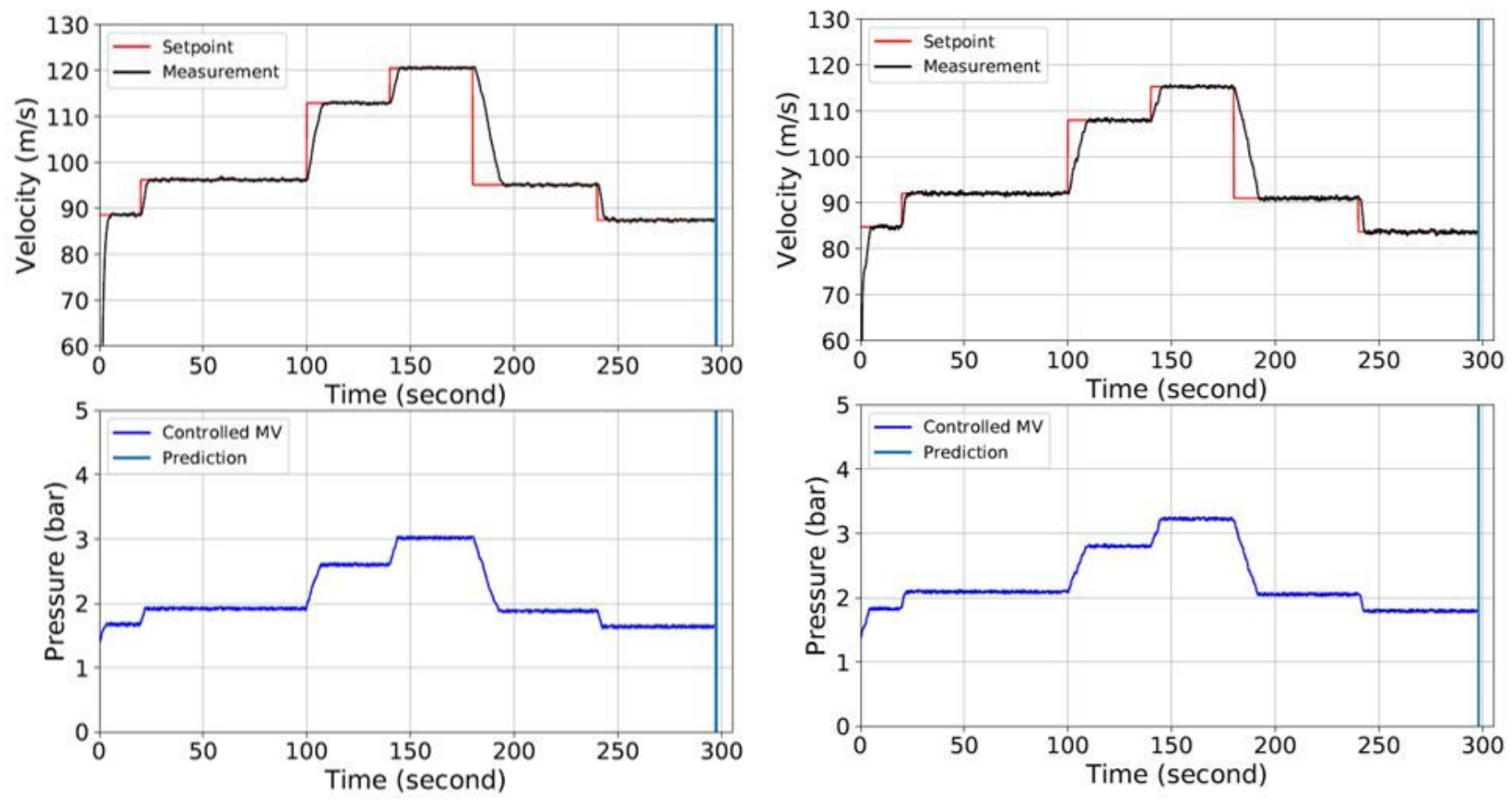

(a)

(b) 
Figure 16

Results of control soft-launch with different values of intensity of the shot peening machine with ASR 70 peen type for different media flowrates: (a) media flowrate of $3 \mathrm{~kg} / \mathrm{min}$ and (b) media flowrate of 5 $\mathrm{kg} / \mathrm{min}$.
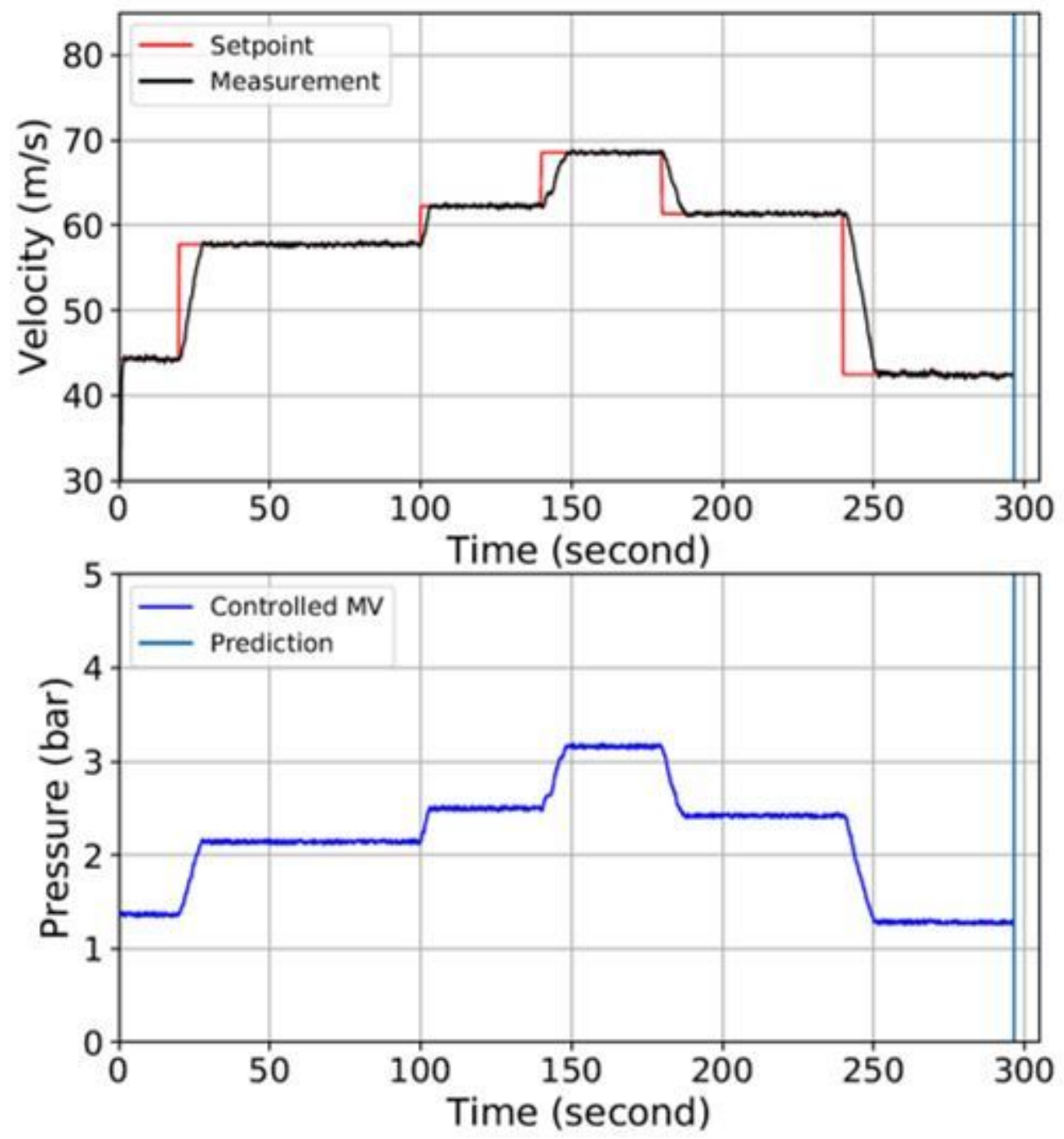

\section{Figure 17}

Results of control soft-launch with different values of intensity of the shot peening machine with ASR 230 peen type for different media flowrate of $3 \mathrm{~kg} / \mathrm{min}$. 